\title{
Contour Crafting Simulation Plan for Lunar Settlement INFRASTRUCTURE BUILD-UP
}

\author{
NIAC Phase-I Final Project Report - October 2012
}

\author{
B. Khoshnevis, A. Carlson, N. Leach and M. Thangavelu
}

\section{INTRODUCTION}

Economically viable and reliable building systems and tool sets are being sought, examined and tested for extraterrestrial infrastructure buildup. This project focused on a unique architecture weaving the robotic building construction technology with designs for assisting rapid buildup of initial operational capability Lunar and Martian bases. The project aimed to study new methodologies to construct certain crucial infrastructure elements in order to evaluate the merits, limitations and feasibility of adapting and using such technologies for extraterrestrial application. Current extraterrestrial settlement buildup philosophy holds that in order to minimize the materials needed to be flown in, at great transportation costs, strategies that maximize the use of locally available resources must be adopted. Tools and equipment flown as cargo from Earth are proposed to build required infrastructure to support future missions and settlements on the Moon and Mars.

The goal stated in our Phase I proposal was a high fidelity demonstration at D-RATS to be conducted at the conclusion of the Phase II study. In the course of the Phase I study, however, it became clear that such demonstration was neither possible (due to the maximum Phase II budget limitation and the cost of NASA assets and related overhead expenses to support such demonstrations), nor necessary (due to NASA's low TRL expectation of Phase II results). These important facts were revealed to us only after interacting with the NIAC administrators and meetings with potential future partners at JPL and KSC. Accordingly, it was decided by the team that in order to make best use of resources we should investigate novel directions in the adaptation of our fabrication technologies by using in-house laboratories and to produce truly useful technologies and data, and then proceed with high fidelity demonstration at a later opportunity when sufficient resources become available. Furthermore, we have recognized that in addition to our building scale 3D printing technology called Contour Crafting, variations of some of our other fabrication technologies under development as well as some new technologies dedicated to planetary applications that we plan to develop are suitable for construction of infrastructure elements such as regolith based ceramic tiles.

Our Phase I activities have been involved on many fronts. So far we have successfully engaged in team building efforts, we have conducted extensive literature review in related domains and engaged in architectural conceptual design of planetary outpost elements, we have performed materials and process studies, built experimental machines and conducted laboratory experiments, conducted structural design and analysis studies, jointly taught a new Moon Studio architecture course, created several high fidelity visuals, made presentations at three conferences (an additional presentation scheduled for a fabrication 
conference will be held in August 2012), published several research articles on various aspects of our project in engineering and architectural proceedings and journals, and participated in several interviews for related articles and television programs that appeared in acclaimed international media. The following sections present some of these activities in more detail.

\section{TEAM BUILDING}

In the course of our Phase I study and through the informative NIAC conferences, we have made highly synergetic alliances with esteemed groups of NASA researchers. Shortly after the start of the project our team visited the D-RATS site where we made numerous useful contacts with NASA researchers and administrators who were working at D-RATS or visiting the site. At the fruitful NIAC meeting in November 2011 we initiated contact with the KSC team (thanks to the NIAC Program Director who wisely arranged for our poster presentations to be adjacent to one another). Since then we have had numerous interactions with the KSC team and this April we had an extensive meeting with five researchers from KSC who visited USC and our laboratories. Our group has been exploring other synergetic partnerships as well. Notably, we had a meeting with the JPL ATHLETE group with whom we have had several useful meetings and exchanges. The PI also visited MSFC to meet with the group specialized in radiation shielding. The result of these interactions is the synergetic partnerships from which our NIAC project benefits.

We have also engaged two engineering graduate students (one being under scholarship support and working as a $50 \%$ RA solely on the NIAC project), two graduate architecture students who concentrated on visualization projects, and one undergraduate astronautics student (also under scholarship support).

\section{CONCEPTUAL INFRASTRUCTURE DESIGN}

Lunar structures can be broadly classified into pressurized habitable environments and unpressurised infrastructural elements. Early advice from NIAC program office recommended that we focus on lunar infrastructural elements as essential precursors to human habitation. Accordingly, the decision was made to focus on infrastructural developments as opposed to pressurized habitable environments. The infrastructure elements include landing pads and aprons, roads, blast walls, shade walls and hangars for protection against thermal radiation and micrometeorites

We first concentrated on the landing pad and road requirements and will be concentrating on blast walls and hangars for the remaining part of the project. Lunar vacuum and low gravity will make it very difficult to contain or curtail high energy debris that results from direct lander exhaust plume impingement on the exposed, free and loose surface regolith. The extreme natural environment of the Moon coupled with the reference Altair-class (45-50MT) lunar lander touchdown profile will create a very challenging dust and debris environment for safe sortie operations. Ground effects will be far more severe than experienced during Apollo missions (Mason 1970). Review of recent literature clearly points to the need to provide stabilized surfaces for landing heavy payloads (Lumpkin 2007, Metzger 2008, Khoshnevis 2012, Sengupta 2012). 
Site Selection: Site selection for lunar lander sortie operations is of the utmost importance. A strategic location will provide several advantages. They include:

- Safety - Good approach and lift-off trajectories (and abort), and maximum windows of opportunity for routine operations, avoiding overflights above sensitive locations, landmark identification and pilot landing target visibility (Eppler1992, Kerrigan 2012)

- Least fuel expenditure (depending on landing site altitude)

- Terrain character - plains vs. highlands, bedrock vs. loose regolith

- Steady surface/terrain temperature

Lander Terminal Phase Effects: The reference RL-10B main engine cluster core exhaust of the lander, during the terminal descent and touchdown phase of operations, upon low velocity translation toward and hovering maneuver over the touchdown area, just before main engine cut-off and setting down, will exert around 50MT reaction loads over a very small footprint of approximately $10 \mathrm{~m}^{2}$. This force will be compounded by the intense heat and pressure of the exhaust, even if only for a small period of time. The rapid transient temperatures and pressures, further aggravated by low lunar surface ambient (depending on site), will cause severe stresses on the landing pad materials and need to be carefully studied and taken into account for safe and reliable design over the commissioned life cycle (assumed to be 100 landings over a 10 year timeframe).

Landing Pad Options Under Study: One way to accommodate this extreme transient temperature and dynamic pressure pattern is to reinforce the core of the landing pad with appropriate materials and design features to mitigate the exhaust effects. The $\mathrm{CC}$ technology and other augmenting methods that we have newly explored may offer a way to create and inlay refractory tiles in such a manner as to be able to dissipate the heat and energy of the lander engines effectively.

Several other options for landing pads exist including locating and appropriately preparing (tooling and shaping) naturally occurring expanses of bedrock before applying CC technology, and we are studying these alternatives.

The landing pad apron has much less stringent requirements than the landing pad center segment and as such sulfur concrete may be a reasonably good candidate for its construction. We are considering several different methods or a combination of these methods for road construction. These include construction by sulfur concrete, by extruded molten regolith, by melting regolith in place without extrusion, and by using strong ceramic tiles made of sintered regolith and possibly grouted by sulfur concrete or molten silica.

Our concept designs of landing pad, apron, blast walls, and road and hangar robotic construction scenarios are depicted in visualization shown in Figures 1, 2 and 3. 


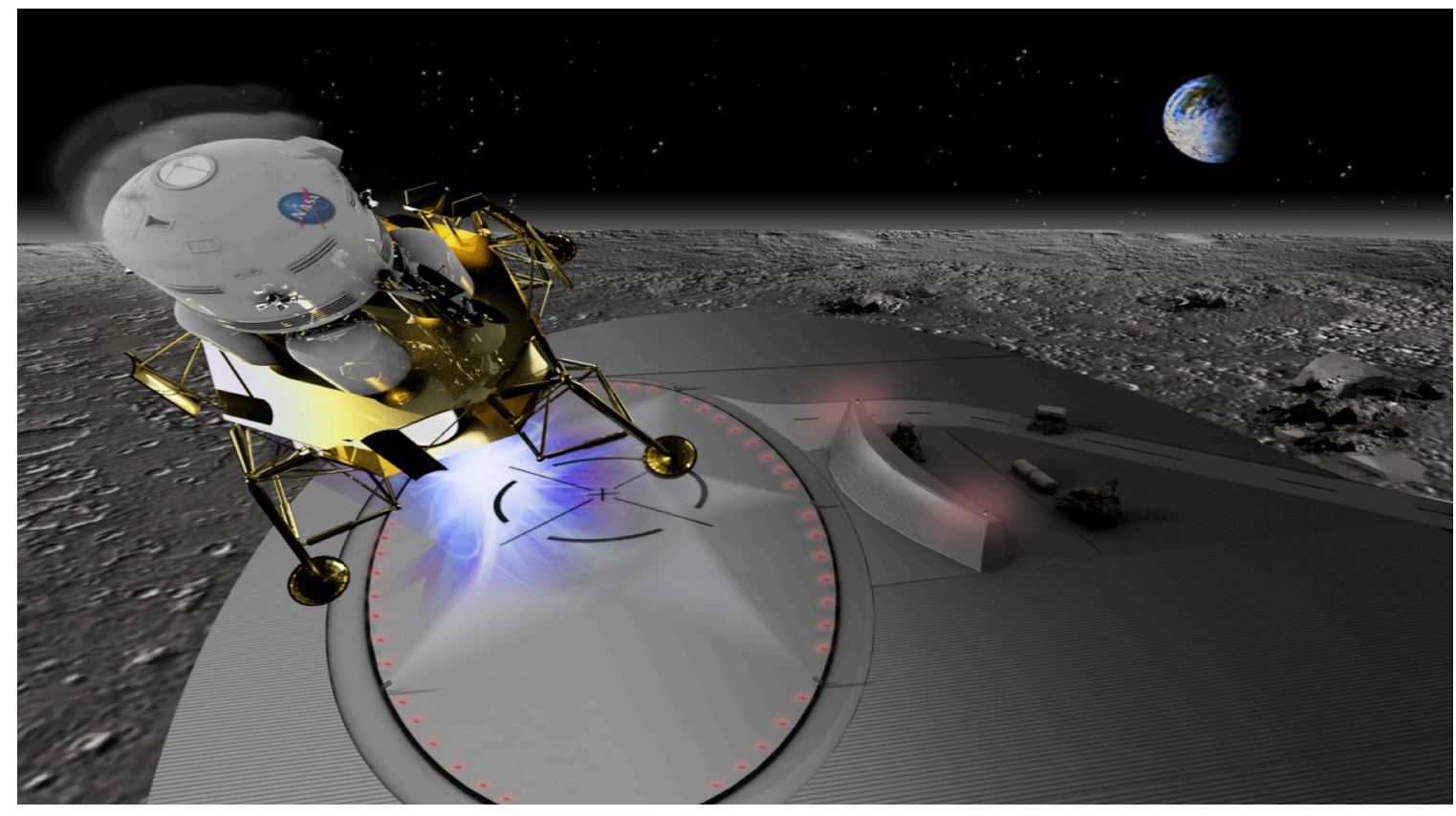

Figure 1. A lander is shown coming in to land on a lunar landing pad. The landing pad has been designed as an ellipse with its length in line with the direction of landing and takeoff with a central landing area lit up by lights, surrounded by a broader dust-free apron. A blast wall is also visible, protecting the entire settlement and items of equipment stored behind it.

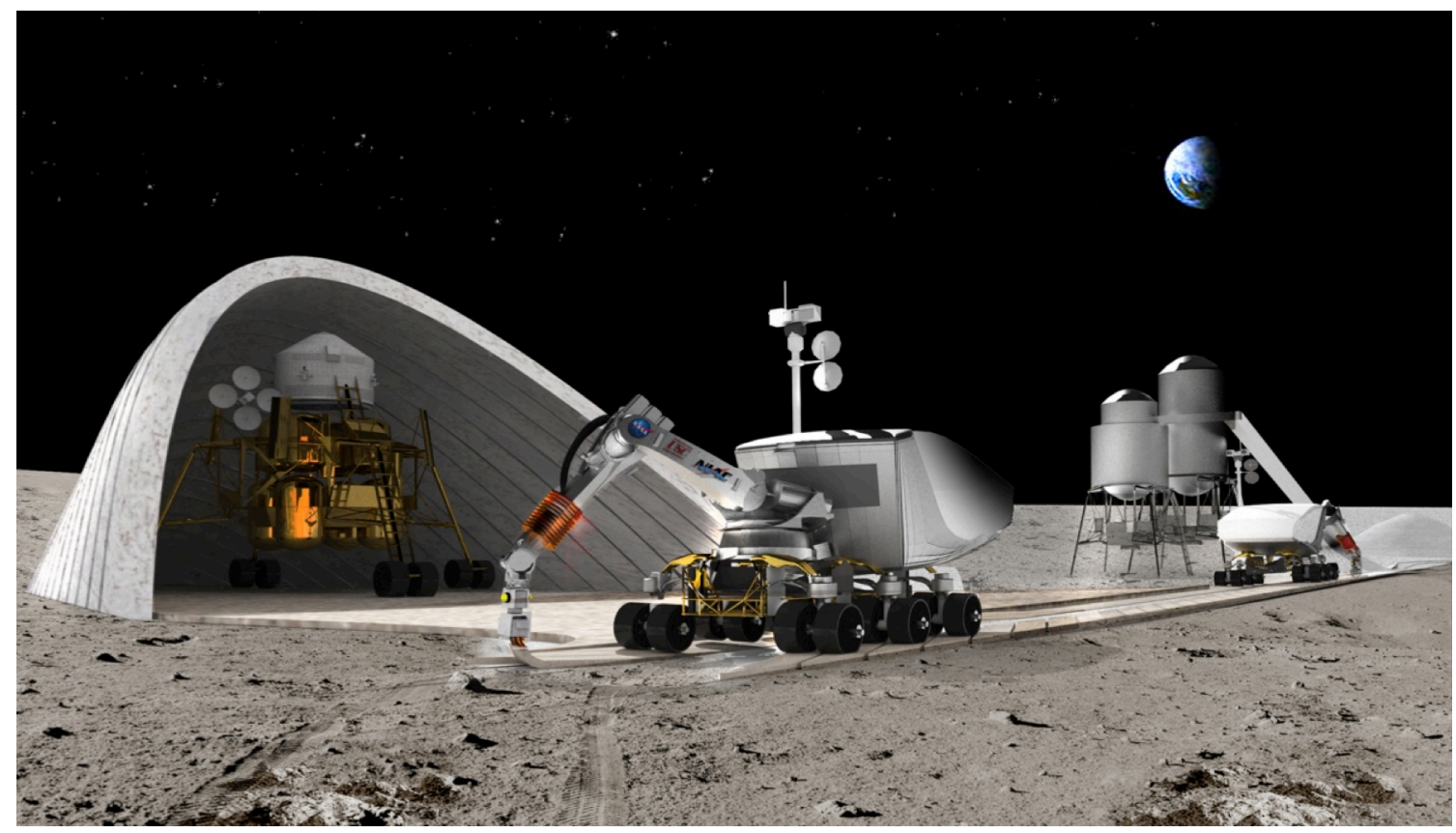

Figure 2. A Contour Crafting robot is shown here printing a road in front of a parabolic hangar structure housing a lunar lander. In the background can be seen a plant intended for processing regolith that will be used in the construction process. 


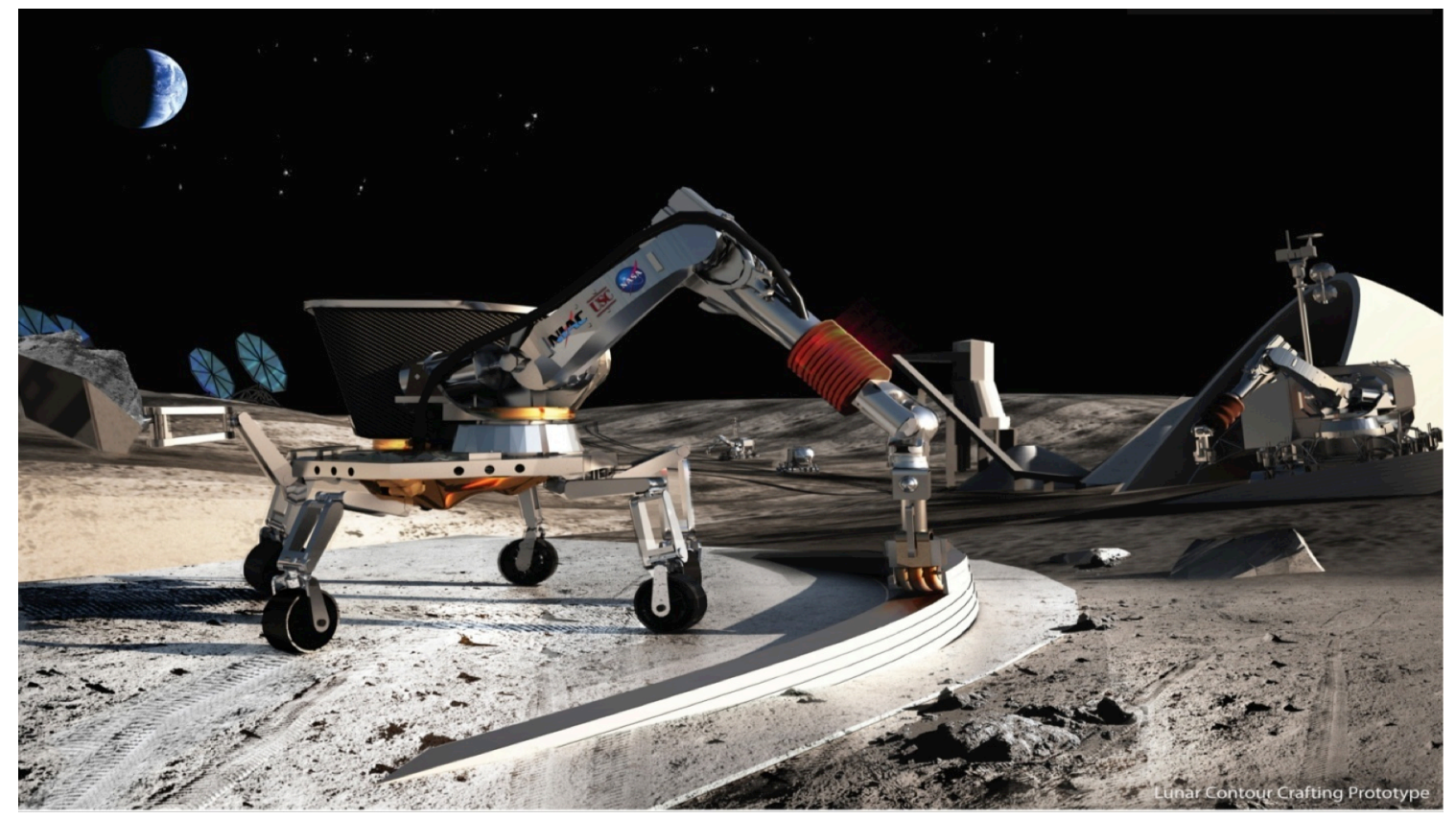

Figure 3. A Contour Crafting robot, housed on an 'ATHLETE' rover, is shown here printing a parabolic vault structure out of processed regolith. The structure is intended to house a lunar lander or other equipment, and is unpressurized. The parabolic form has been adopted, because it is structurally efficient and lends itself to the Contour Crafting mode of construction. In the background can be seen an array of solar panels intended to supply power to the robot.

\section{DESIGN VALIDATION}

Our efforts in Phase I have been on selection of infrastructure components of highest importance to future settlement buildup. We have developed an analytical process for assessment of each type of infrastructure component selected that will be the focus of future research. We have identified the governing environmental factors that will influence the construction sequence, form and massing of each component. The raw materials, binding process and physical abilities of Contour Crafting are also parameters that will influence the resulting structures.

\section{Infrastructure elements}

The following are the originally proposed structures that were being considered for building using a CC system and employing ISRU materials at the D-RATS field test and simulation site.

A lunar landing pad and blast apron: Since it is essential to have a solid, stabilized surface for repeated lunar landing and lift off sorties, an economically viable and safe landing zone must be identified. We expect the LCROSS /LRO mission data and follow on missions including the current GRAIL mission, named FLOW and EBB, as well as other proposed robotic rovers to provide invaluable data on such site selection that is safe for approach, touchdown and lift-off operations as well as abort to orbit trajectories, if needed. 
The landing pad surface could potentially be patterned to diffuse the high thrust loads of about 40MT and severe heat imparted on it by the descent engines. A blast apron to curtail ejecta is also needed to keep hazardous projectiles from striking/damaging high value assets in the vicinity $(3-5 \mathrm{~km})$ of the landing zone.

Some regolith stabilization surrounding the landing and lift off zone is also under consideration. CC tools and innovative sintering techniques being studied by our KSC partners may play a useful role in wide area lunar surface stabilization.

A dust-free stabilized road from the landing pad to Habitat Zone: For repeated transport of cargo and crew from the landing zone to the habitat, it is perhaps prudent to have a system that does not aggravate lunar dust effects on transport systems such as pressurized or unpressurized rovers. Paving a dust-free hard-topped road is one alternative. A light rail is another option. Both of these options are being explored for lunar CC application.

A dust-free platform for setting/erecting/deploying the habitat components: It is well known that lunar dust will hamper buildup as well as routine activities around the settlement. Therefore all dust prevention measures are being evaluated. Again, lunar CC application may provide an option to pattern a dust-free platform that traps, repels and thus ameliorates dust transport to the habitat zone and contamination of lunar settlement interiors.

Thermal shade walls and protective micrometeorite $(\mathrm{mm})$ shields: Once the habitat components are assembled, in order to operate it at optimum safety and energy efficiency, the complex must be covered with a suitable mm shield that will also regulate thermal control. Patterns, louvers and other openings will be built into the surface of this protective enclosure to facilitate thermal regulation during lunar solar diurnal cycle. Unpressurised shelters in a variety of shapes and sizes to accommodate a range of activities from storage of sensitive cargo to structures that allow service and change out of lunar lander components such as crew capsules and ascent stages are also viable using CC systems, but such activity are proposed for the future and were not part this investigation.

A Communication and Observation tower: Since the high ground provides a better view, especially in the lunar case where the horizon is just $3 \mathrm{~km}$ away, an observation tower for a suite of cameras and communications equipment has been suggested in earlier studies. A tower may also be located high enough to be able to directly observe lunar lander operations. Such a tower may be placed upon a naturally occurring peak, or designed and built using the CC system employing ISRU methods. The height of such a tower is dependent on site parameters.

\section{Construction structural and environmental issues}

The proposed layered deposition of in situ processed materials requires a compression-based structure due to possible lack of in situ materials to reinforce regolith concrete with sufficient tensile strength (although basalt fiber reinforcement could be a possibility). Forms must be developed to ensure a compressive load path or that require a minimal amount of tensile reinforcement of Earth based materials such as the lightweight carbon fiber composites. However, with parallel advancements in material extraction, metals from regolith could be reintroduced to the sintering or microwave melting of the regolith to create a composite matrix that would have more substantial tensile properties which could reduce the material and time required for construction. Less energy is needed on the Moon to lift and move materials because of 
low lunar gravity. Because the proposed structures are predominantly compressive, buckling is an issue to consider. Again, the advantage on the Moon is that the buckling load will be one sixth Earth gravity buckling loads allowing for more slender structures reducing construction time, material and energy.

In-situ processes of molten regolith for robotic deposition require careful investigation of melt chemistry, flow properties, and the cooling process to yield structures sufficiently strong to withstand tensile forces that the different infrastructure forms may be subjected to under thermal gradient and/or blast loading.

Dust is a primary concern and architectural designs must address this concern directly. Meteorites, radiation and light intensity can be a problem. The regolith concrete must form the desired inhabited and uninhabited spaces as well as resist and provide durability against meteorites, radiation, thermal loading and direct sunlight. An optimal solution that takes advantage of increased buckling strength to minimize the material but still resist meteorites and provide a barrier for radiation will be sought.

Severe temperature differences exist between stark daylight and shadow, and even more drastic surface temperature swings can be found in the diurnal thermal cycling, not to mention the rapid changes as vehicles and their systems move about on the sunlit lunar surface. Fixed structures induce internal stresses based on thermal gradients and temperature differences from initial construction temperatures. A structure that is partially shaded can develop large unbalanced thermal stresses. Uniformly heated or cooled structures can be designed more readily to accommodate thermal expansion and contraction and minimize the unbalanced stresses that may introduce tension and cracking. Severe temperature differences may also arise based on sun angle. Sunlight can be harvested, and if consideration is being made for developments near the South Pole, this will be necessary to reduce heating demands for habitation and for fluidity of the concrete regolith during construction.

Solar intensity will influence both architectural and structural design. To avoid extreme variation, forms need to be sought with similar sun exposure throughout their exposed surface. Particular attention will therefore need to be paid to the geometry and behavior of the sun with regard to the solar envelope. Layout of Moon development should carefully consider the long shadows that will occur at a polar development to ensure equal exposure. Shading walls can assist in maintaining a smaller range of temperature variation and can be slender due to increased buckling capacity with lower gravity and also due to lower wind and seismic lateral loadings. Thermal blankets will need to be deployed extensively, especially on dynamic structures, surface vehicles and systems that are subject to rapid temperature swings as they execute their missions.

The exterior surfaces of permanently located structures should also be form-found to counter the thermal gradient of the exposed side to the shaded side to minimize development of tension on any surface. A double wall system could be used to heat gases or fluids that could be used for any development needs including conditioning air and water for human use or for irrigation of moon farming. It could also be used as a geothermal heat pump to increase temperatures above the low below surface levels to temperatures within the space required for experiment or temporary habitation.

Incidently, water is also a very good material for radiation shielding. $30 \mathrm{~cm}$ thick water or ice is sufficient protection, and if methods can be devised to mine and use lunar water for this purpose, this procedure could substitute for a much thicker $3.5 \mathrm{~m}$ coat of lunar regolith that is recommended for the same radiation shielding effectiveness. 


\section{Parameters influencing infrastructure design}

We have reviewed information that will assist in determining a figure of merit for the Contour Crafting construction of infrastructure on the moon. We have also developed a process to conduct multi-modal analysis using Abaqus, mode frontier and other software to assist in finding the optimal solutions for multi-objective constraints. The main parameters influencing structural performance include:

Materials

- Regolith binding agents

- Mechanically hewn and shaped lunar rock

- Crushed lunar aggregates in a range of shapes and sizes

- Powders and other fines for extensive use in paints and markers

- Extracted metals

- Regolith with extracted metal matrix

- A range of fiber glass materials - fibers to fabrics

- Structural properties

Construction

- Tele-operated

- Some human supervision - co-robotics

- Sintered

- Dry packing

- Other deposition techniques

Structures

- Landing pads

- Roadways

- Equipment shelters

- Shade walls

- Tensile Fabric structures

- Thermal blankets

- Platforms

- Other infrastructure (solar panels / communication equipment)

Environmental Factors

- Dust

- Micrometeorites

- Radiation

- Thermal issues (shade vs. sunlit, diurnal, regional variation)

- Low lunar gravity

- Cooling rates of sintered regolith

\section{Economics}

- Form optimization accounting for crew and robot safety issues during buildup and over the lifecycle of structures 
- Form optimization to minimize materials and tools

- Form optimization to minimize construction time

- Energy economics

- Form optimization to minimize risk to desired performance level

- Layout optimization for same parameters above

Note that Contour Crafting is an enabling technology. Parameters listed above affect a whole range of lunar materials, systems and construction methods, and we are currently studying how to utilize Contour Crafting in the most effective way, applying synergies with existing and proposed NASA tools, systems and strategies.

Transport, deployment, performance, endurance/maintenance and expansion cost will be common bases for assessing both the robotic or co-robotic techniques and the different infrastructure elements assessed.

\section{Infrastructure}

Initial requirements for infrastructure will be landing pads, landing aprons and blast walls for protection of equipment or resources close to the landing sites. Unless forfuitous naturally protected sites are located from data being scoured currently, research stations or settlements will need to be further away from the landing path to avoid damage from rocket ejecta and secondary hyper-energetic regolith projectiles. This will require construction of roads, dust-free platforms, shade walls, equipment storage hangars and radiation and meteorite protection shelters. All of the above infrastructure can be built from regolith and other ISRU materials utilizing several methods of robotic fabrication investigated in this proposed study. Maximizing ISRU using robotic construction technology as an enabler is the prime driver for this architecture.

Several construction tasks will be necessary to achieve safe and productive conditions for extended human presence at extraterrestrial sites (Mueller and King, 2007)

- Provide hard-surfaced thermally stable and transient pressure tolerant landing pads to reduce the generation of abrasive rocket engine blast ejecta at landing sitesBuild blast shields to deflect residual ejecta away from personnel and equipment.

- Provide smooth-surfaced utility roads to increase the efficiency of vehicular transport.

- Build level and secure foundations for civil engineering structures

- Provide surface stabilization to mitigate the effects of regolith dust degradation of equipment

- Install radiation shielding and emergency shelters for personnel in excess of that which can be affordably launched from Earth.

- Construct equipment storage and servicing hangars in a dust free environment.

All of the above structures and their allied subsystems must perform optimally over specified lifecycle with built in tolerances for graceful degradation.

\section{Structural Design and Analysis}

We have identified the structures to investigate in Phase I with input from NASA regarding their priority and have developed a framework for finite element analysis (FEA) of these structures. The analyses required include implicit and explicit solvers, computational fluid dynamics, coupled Lagrangian-Eulerian 
analyses, heat transfer, shape optimization, shock, blast, contact, damaged plasticity, fracture and adaptive remeshing. Cyclic and dynamic transient loads are assumed, and worst case scenarios are also examined.

For the landing pad and apron, boundary conditions and loadings include lander thrust, exhaust heat and dynamic loads, solar energy, and robotic construction interface with lunar soil or rock. The issues we will investigate with the multi-physics model include repeated heating and thrust from multiple landings, ejecta from fuel and dust, hard landings, micrometeorites, and buckling or cracking potential of the pad surface from the extreme environment. High impact loading and thermal stresses coupled with low tensile strength will influence construction joint pattern and dimension.

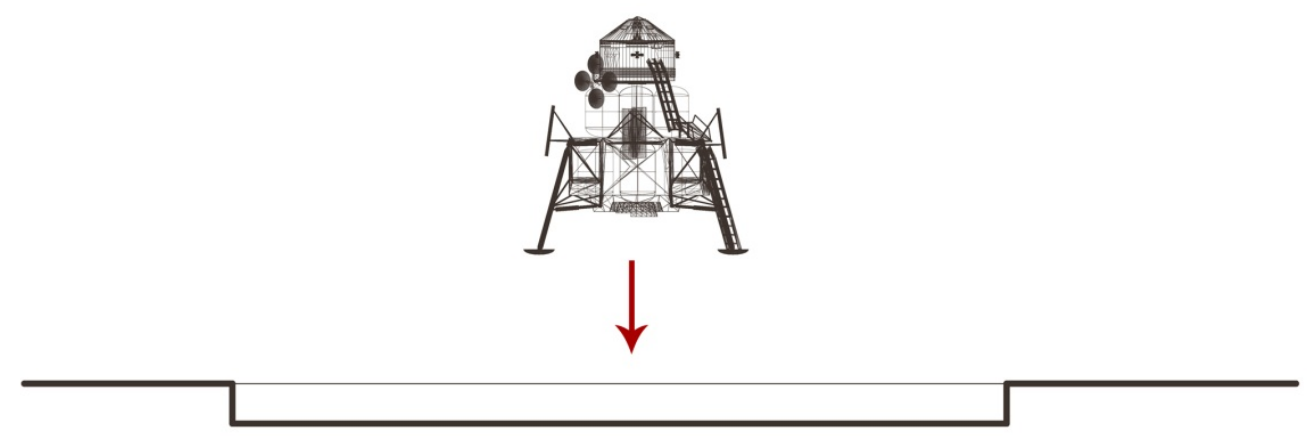

Figure 4: Landing Pad and Apron Boundary Conditions and Loading

For blast wall design, our finite element model will again look at rocket exhaust variables including thrust, temperature, ejecta from fuel and dust, and the robotic construction interface with lunar soil. The intent of the blast wall is to protect nearby storage or facilities and protect distant settlements from landerinduced hyper-velocity clouds of lunar dust. In future research we intend to do a shape optimization study of the wall to minimize all of the following: ejecta reflection to the lander, deposition of ejecta on nearby storage and distant settlements, and deterioration.

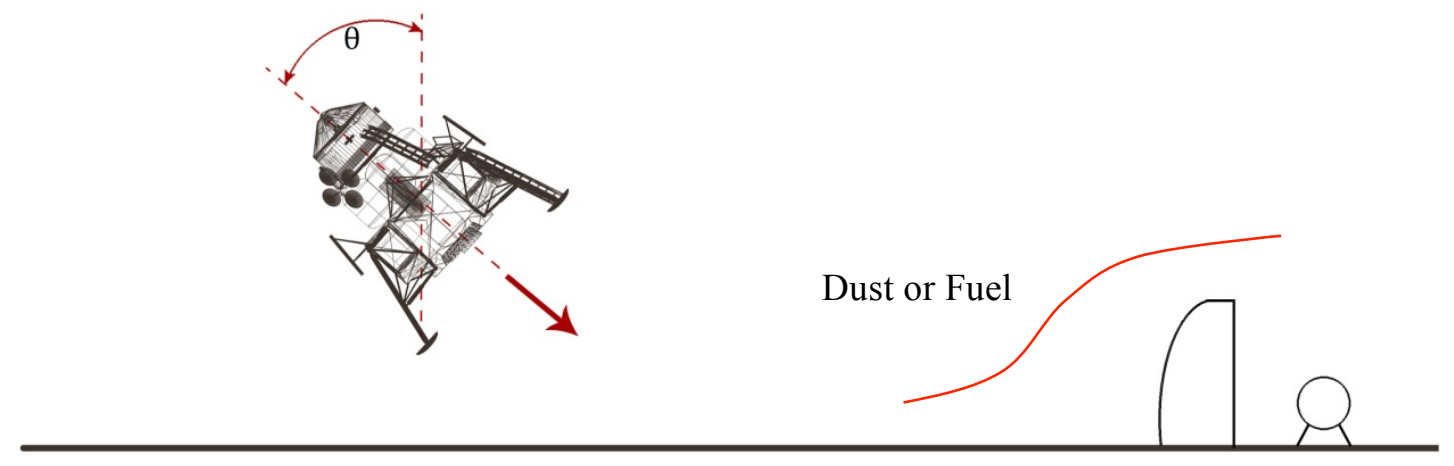

Figure 5: Blast WallBoundary Conditions and Loading

We are also developing models of roadways and hangar or storage structures. For the roadways, we will investigate solar energy, rover loading and soil/structure interaction considering maximum payload, traction and buckling and cracking potential from high temperature or load gradients. 


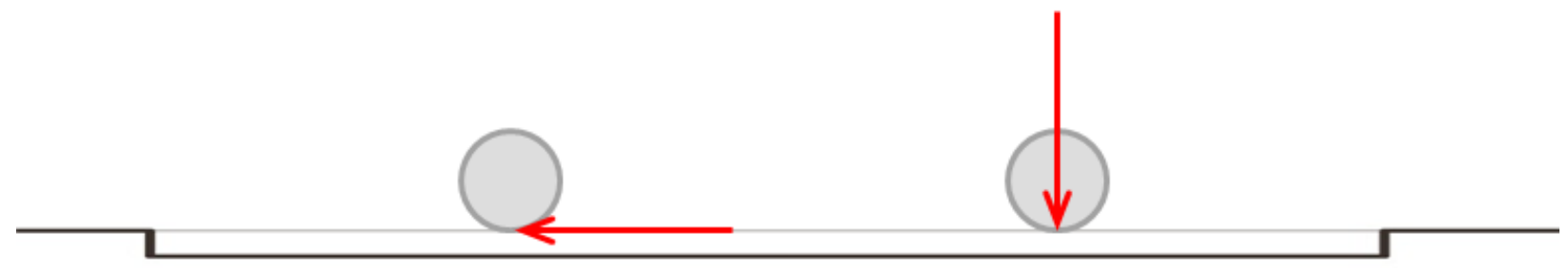

Figure 6: Roadway Boundary Conditions and Loading

For hangars, boundary conditions and loadings include self-weight, solar energy, micrometeorites and soil/structure interaction. Issues to be assessed include thermal stress/strain, stability, crack propagation and radiation protection. Constructability and sequence will also influence our recommendations for hangar overall size and shape.

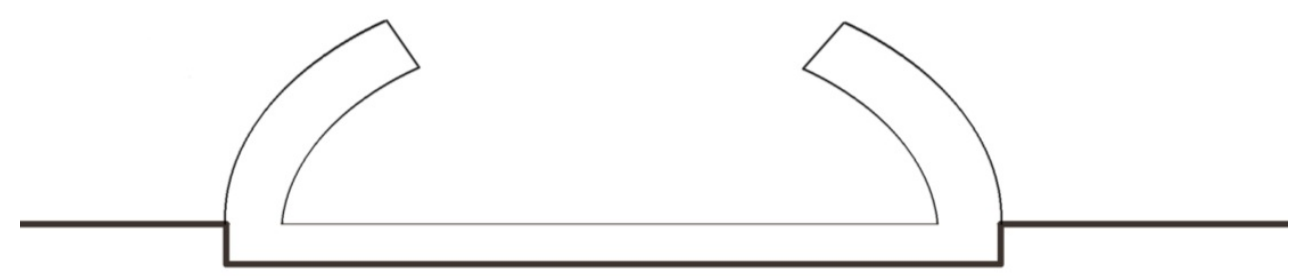

Figure 7: Hangar Boundary Conditions and Construction Sequence Stability

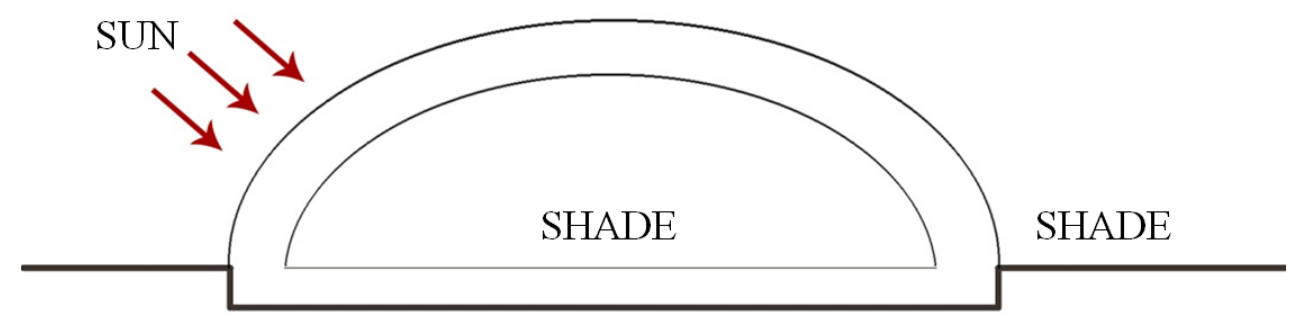

Figure 8: Hangar Thermal Loading

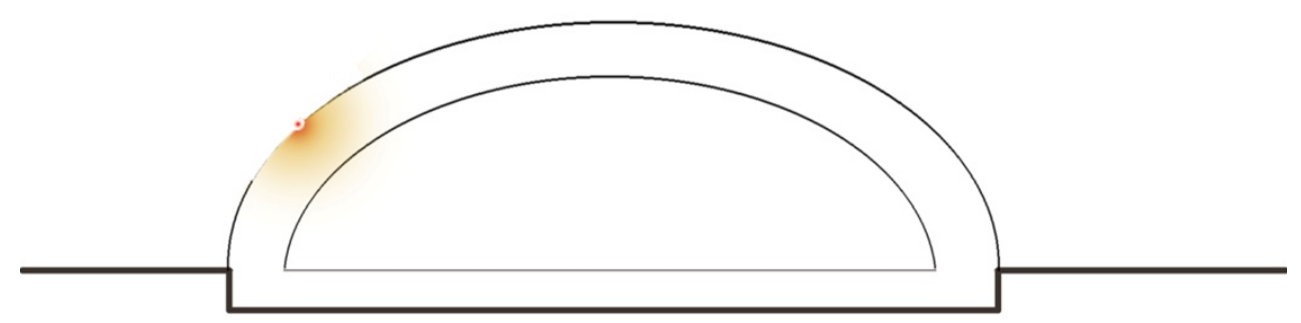

Figure 9: Hangar Micrometeorite Impact Loading

We are currently building up our database on reliable information about the strength, thermal and other mechanical properties of hydraulic, sulfur based, melted and sintered regolith concretes in the literature and will be using assumptions based on other known materials as well for our modeling. 


\section{Calibration of material processing performance}

Performance metrics include strength, hermeticity, durability under lunar thermal cycles, and adhesion to underlying base layers. Additional metrics apply to processability, including melt temperature, viscosity, heat capacity, and resistance to thermal shock. The technical approach aims at assessing suitable mineral formulations and grit sizes for robotic construction that are being developed concurrently at Kennedy Space Center, and demonstrating performance metrics through simulation and testing of small samples made in USC laboratories. Additives (available in situ) will be selected to adjust melt viscosity and flow characteristics. Predictive modeling using FEA, fluid dynamics, and thermal equations will support the materials effort. These models (calibrated to fit our experimental results) will help guide the necessary layer thicknesses, rheology, build speed, and reinforcement architecture.

\section{MATERIALS AND PROCESSES FOR CONSTRUCTION}

\section{Construction using ISRU materials}

The focus of our study is on structures built employing extensive use of local materials, or In Situ Resource Utilization (ISRU). Current lunar settlement buildup philosophy holds that in order to minimize the materials needed to be flown in, at great transportation costs, strategies that maximize the use of locally available resources must be adopted.

Tools and heavy equipment flown as cargo from Earth are proposed to build required infrastructure to support future missions and settlements on the Moon. Roads and landing pads, equipment storage units and platforms and shade walls may all be built from lunar rock and other ISRU materials utilizing sintering/melting with Contour Crafting (CC) construction. Additionally, the robotic system handling the CC apparatus may be outfitted with appropriate end effectors to be used to precisely emplace ISRU building components such as slurry, blocks rough-hewn rocks, tiles and other surface finishes as required to build up a dust-free zone around the lunar settlement and activity sites. Maximizing ISRU using Contour Crafting technology as an enabler is the prime driver for this architecture. Such an effort will produce a figure or merit for the $\mathrm{CC}$ technology while ferreting out the limitations of undertaking such a complex endeavor on other planets.

The lunar surface is scattered with minerals and compounds that may be readily accessed to produce metals, glass, bricks, paints and other materials that are necessary for the construction of permanent settlements and infrastructure. Sulfur has also been proposed as a binder but our focus will be on sintered regolith as the first choice with water or sulfur based regolith concretes considered as alternates. We also recognize the possibility of using ISRU extracted metals to reintroduce as discrete elements or into the regolith mix as a binding matrix to develop tensile strength in the materials. This effort could be done in collaboration with NASA investigations of lunar mining and material processing. The design process developed would first assess to what extent infrastructure can be built without tensile reinforcement to avoid the complexity of requiring metals processing for initial infrastructure.

In the course of our current project we have considered a variety of practical construction material for different planetary structural applications. 
In 2009 data from the Indian lunar orbiter spacecraft Chandrayaan-1 indicated that water exists all over the Moon and that repositories are viable in the polar regions. Recent data indicates large reservoirs in the polar regions, and NASA has plans to quantify this lunar resource as early as possible. Water based lunar concrete may be considered which could allow straightforward regolith stabilization and dust suppression, however, creation and handling of hydraulic concrete mix in vacuum may be a near impossibility. Use of hydraulic concrete inside pressurized structures seems to be a more feasible proposition. Accordingly, our years of research on hydraulic concrete construction for terrestrial applications using Contour Crafting and the resulting technological solutions will be applicable to extraterrestrial condition with relatively minor alterations beyond handling hydraulic concrete mix in a high or low temperature and possibly in near-vacuum environment. We have hence decided to focus our attention on other construction materials including sulfur based concrete, molten regolith concrete, and sintered regolith.

\section{Technology using Sulfur Concrete}

Creation of sulfur-based concrete is fairly straightforward once sulfur is extracted from regolith. As shown in the top portion of Figure 10, sulfur concrete is made of about $80 \%$ regolith and $20 \%$ sulfur. Contour Crafting structures using sulfur concrete requires mixing the two components and then extruding the dry mix through a CC nozzle barrel that is heated to $130 \mathrm{C}$, the melting temperature of sulfur. Sulfur concrete structures can have a compressive strength of $3000 \mathrm{psi}$ which is higher than the strength of most ordinary hydraulic concrete structures, such as those built with concrete blocks.

Extrusion of granular abrasive material is never straightforward. Lacking water which serves as lubricant to ease the concrete flow, we expect the extrusion of the highly viscous and abrasive sulfur and regolith mix to be challenging. To study the problem we have created an experimental device shown in the lower section of Figure 10 under our Phase I project. In this device a gear motor turns an auger that forces the dry mixture of sand and sulfur out of a vibrating hopper and into a hot barrel and nozzle. The

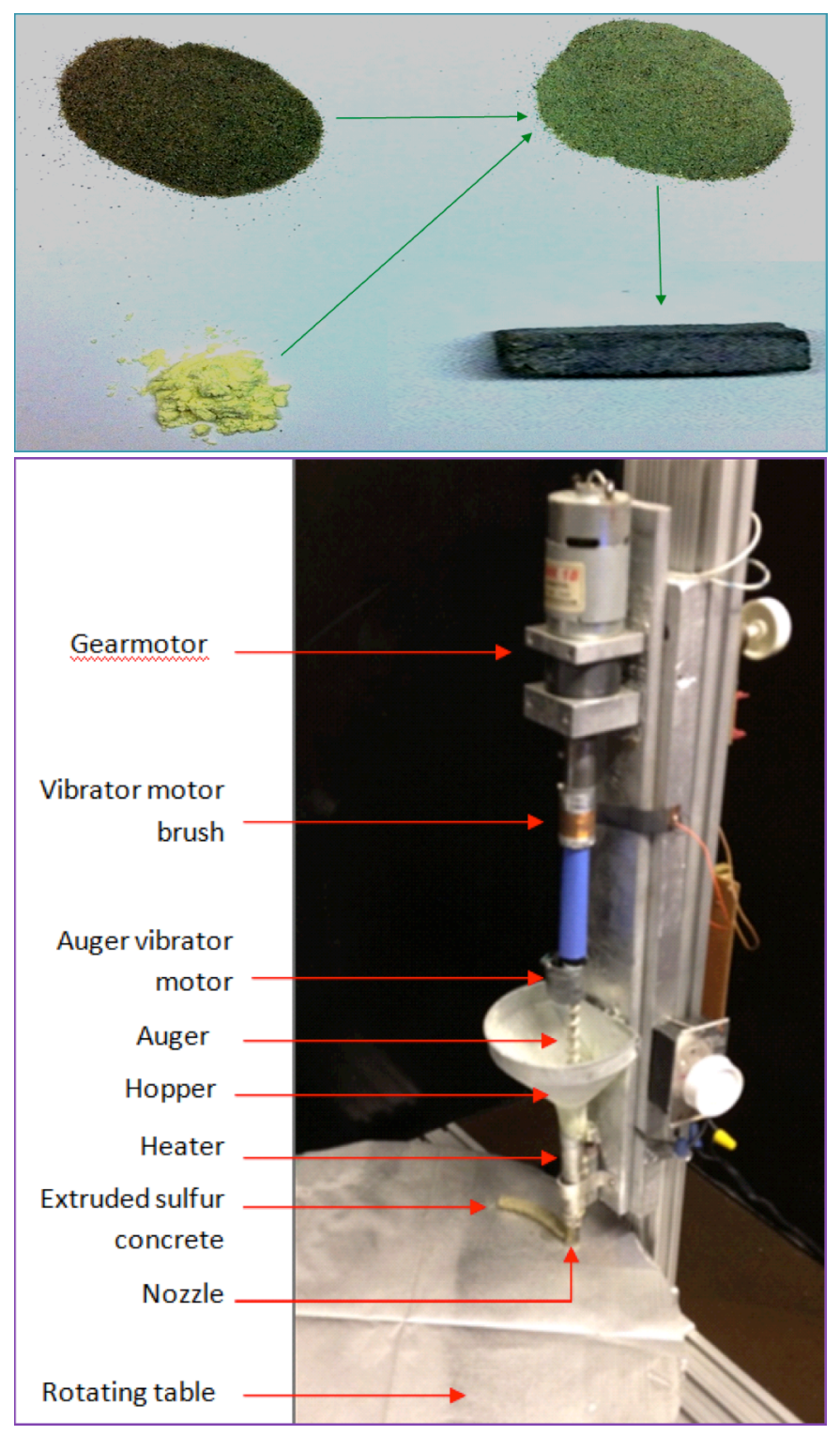

Figure 10. Top: Sulfur, sand, sulfur/sand mix yielding sulfur concrete; Bottom: Experimental machine for extrusion testing of sulfur concrete 
auger is also equipped with a vibrator to prevent possible clogging. As the mixture is pushed inside the hot barrel of the extrusion nozzle, the sulfur portion heats up in the upper portion of the barrel and melts in the lower portion. The extrusion process may take place without clogging only for a few seconds until the "bridging" phenomenon causes a few particles of sand to create an arch against the flow direction and the two arch bases push against the inner walls of the barrel causing complete clogging. Under such a circumstance vibration could overcome the static friction and clear the clogging problem. Vibration may be applied to the barrel or to the auger. Vibrating the barrel could be problematic as the barrel is solidly attached to the rest of the structure for stability. Barrel vibration may also eventually damage the heater filament that heats the barrel to melt the sulfur; therefore, it is best to vibrate the auger. Furthermore, it is best to minimize the vibration period only to occasions of clogging because too much vibration causes segregation of sulfur powder and aggregate particles in the upper portion of the extrusion barrel.

We have devised a hard-wired controller that activates auger vibrator only at clogging times. This is done by sensing the gear motor current which increases as beginning of clogging increases the motor load. The more serious the clogging the higher the motor current becomes. A circuit activates the auger vibrator with a vigor that is proportional to the gear motor current. At normal gear motor load levels the vibration motor remains inactive.

The above arrangement seems to be working well for extrusion of sulfur based concrete, however, we are continually investigate methods that will allow extrusion under a variety of conditions, such as extrusion through a nozzle that is attached to a Contour Crafting robot with multiple degree of freedom. Such a nozzle could take any orientation hence extrusion against the direction of gravity must also be possible. Such problems often demand inventive solutions that we have always encountered in the course of our prior CC research.

On Earth sulfur concrete is a relatively new construction material compared with hydraulic concrete. To use sulfur concrete, aggregates is mixed with sulfur powder and then is heated up to around $130{ }^{\circ} \mathrm{C}$ then is cooled down to ambient temperature. The cooled down mix has a compressive strength as high as 17.24 $\mathrm{MPa}(2500 \mathrm{psi})$. Sulfur concrete cures faster than hydraulic concrete, and achieves $90 \%$ of its final strength within 6 hours. Sulfur concrete is more resistant to acidic and salt and hence it has been made into sewage pipes especially in food processing industries. Sulfur concrete also has better properties under large temperature cycles. The aggregate in our experiments is washed dry sand ${ }^{1}$ with a grain size below 1 $\mathrm{mm}$, similar size distribution to that of JSC-1 A. Loosely compressed sand has a specific gravity of $1.64 \mathrm{~g} / \mathrm{cm}^{3}$, and that for regolith simulant is $1.73 \mathrm{~g} / \mathrm{cm}^{3}$, and for sulfur and sand mixture is $1.68 \mathrm{~g} / \mathrm{cm}^{3}$. Both sand and regolith simulant grains are irregular, and the chemical composition does not affect the binding strength.

Sulfur concrete extrusion could realize complete automation, high reliability and flexibility. We have demonstrated that sulfur concrete may be extruded from a nozzle. In the In terrestrial practice heated sulfur concrete mixture is poured into a mold to cool down, which takes time to cool down and move to the construction site to build up the desired structures. The shape of the mold is also limited. By extrusion, sulfur concrete could be extruded in arbitrary straight or curve forms at the construction site, fulfilling different design objects at a much faster rate and without needing molds.

\footnotetext{
${ }^{1}$ We used ordinary sand in most sulfur concrete related experiments to conserve our JSA1-A stock.
} 
A prototype extrusion system has been built in our lab and the concept is demonstrated. The system contains three main parts, feeding container, flow regulator, and heated extrusion elements. The feeding container stores raw materials and mixes them uniformly at a designed weight ratio. In the prototype system sulfur and aggregate are premixed with a weight ratio of $35 \%$ and $65 \%$, respectively. The feeding container is a funnel with the narrow stem around a copper pipe of extrusion usage. While the system is in operation, the mixture flows into the copper pipe by means of vibration. In the real machine to be developed, a larger hopper will replace the funnel.

A flow regulator controls the flow direction of the heated paste mixture and exerts some pressure to the mixture to make it denser and smoother. Currently the flow regulator has a fixed shape and is only suitable for building certain structures of certain shape, like curved walls such as the one shown in Figure 11 is formed. In the new design a flexible regulator compatible to arbitrary shape is expected, and two heated trowels on both sides of the nozzle orifice will be adopted to smooth out the extrudate surfaces.

During the extrusion process the mixture is heated to around $135{ }^{\circ} \mathrm{C}$ and is extruded from the copper pipe by the rotation of an auger. The copper pipe has an inner diameter of $0.96 \mathrm{~cm}(0.38 \mathrm{inch})$, and a length of $10.16 \mathrm{~cm}$ (4 inch). At the end of the pipe, there is an opening about $0.51 \mathrm{~cm}(0.2 \mathrm{inch})$ tall and $1.02 \mathrm{~cm}(0.4$ inch) wide where sulfur concrete could flow through. The opening is connected to the flow regulator. An adjustable heating element of 40 Watts at maximum is closely coupled with the copper pipe and conducts heat to the mixture inside the pipe. An auger with a diameter of $0.95 \mathrm{~cm}(0.375 \mathrm{inch})$ rotates in the copper pipe to extrude the mixture out of the copper pipe as shown in Figure 10. A 12 volt gear

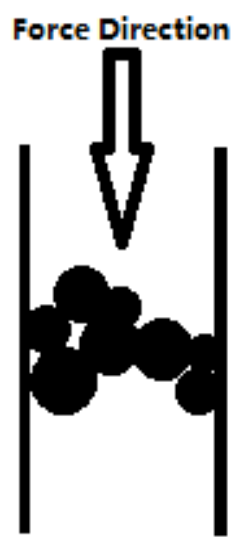

Figure 11. The Bridging effect motor of a ratio of 16:1 drives the auger by a coupler. A vibrator fixed on the auger generates and transmits vibration to the auger as well as to the mixture and the feeding container. The vibration in the auger breaks the arches that can be formed by the bridging effect shown in Figure 11. Without vibration the bridging effect frequently clogs the extrusion barrel.

Each section between two neighboring auger blades (auger pitch) is $1.27 \mathrm{~cm}(0.5 \mathrm{inch})$, and contains a mixture with a volume of

$$
V=\pi\left(r_{o}^{2}-r_{i}^{2}\right) h=0.678 \mathrm{~cm}^{3}
$$

The heat needed for the sulfur to reach $135 \mathrm{C}$ from room temperature $25{ }^{\circ} \mathrm{C}$ is

$$
Q_{s}=35 \% * \rho_{\text {mix }} * V *\left(110 K * C_{s}+H\right)=96.2 \mathrm{~J}
$$

The heat needed for the sand to reach $135 \mathrm{C}$ from room temperature $25 \mathrm{C}$ is

$$
Q_{\text {sand }}=65 \% * \rho_{\text {mix }} * V *\left(110 \mathrm{~K} * C_{\text {sand }}\right)=21.5 \mathrm{~J}
$$

The total energy needed is

$$
Q=Q_{s}+Q_{\text {sand }}=117.7 \mathrm{~J}
$$

In the equations $r_{o}$ and $r_{i}$ are the outer and inner diameters of the auger, $h$ is the pitch of the auger, $\rho_{\text {mix }}$ is the specific gravity of the mixture, $C_{s}$ is the specific heat capacity of sulfur of $0.71 \mathrm{~J} / \mathrm{g} / \mathrm{K}$, and $\mathrm{H}$ is the sulfur heat of fusion of $54.0 \mathrm{~J} / \mathrm{g}, \mathrm{C}_{\text {sand }}$ is the specific heat capacity of sand of about $0.80 \mathrm{~J} / \mathrm{g} / \mathrm{K}$.

During the extrusion process, the auger has an angular velocity of about $30 \mathrm{rpm}$. The copper pipe has a length of $4 \mathrm{inch}$, for this section to get out of the pipe, it takes 8 revolutions and 16 seconds. The actual 
generated heat from the heating element is $640 \mathrm{~J}$. The efficiency of the prototype system is $18.4 \%$, which is quite low due to conduction of heat to the environment.

The extrusion process is continuous without interruptions. In the lunar vacuum environment, the efficiency could be increased to above $50 \%$, and to process 1 cubic meter of sulfur concrete a solar panel of 7 square meters would be needed to work for only 1 day.

Results: The suitability for extrusion of different sulfur concentration is tested. Sulfur concentration of $35 \%$ by mass shows feasibility to extrude continuous and high quality walls. Single layer walls of different sulfur concentration have been built as shown in Figure 12. At a sulfur concentration below $30 \%$ by mass, friction between the auger and the mixture might suddenly increase to a degree that the motor could not rotate even under the strongest vibration. The extruded wall is discontinuous and very loose. At a sulfur concentration above $40 \%$ by mass, melted sulfur will flow out from the nozzle, causing the material to be non-uniform and the structure to be weak because of sulfur dominance. For a sulfur concentration of $35 \%$, the extruded process is smooth and the rotation can be maintained at a constant speed.

The distance between the bottom of the copper pipe and the platform also matters. When the distance is too large the mixture in the copper pipe has no support and will fall down to the platform directly without enough sulfur getting melted. A small distance is preferred if the platform is flat, since concrete flows out in all directions if there is a large gap between the nozzle outlet and the platform.

Our measured compressive strength of extruded sulfur concrete is $7.79 \mathrm{MPa}(1130$ psi) at maximum and 3.65 $\mathrm{MPa}$ (530 psi) for average. This value is lower than
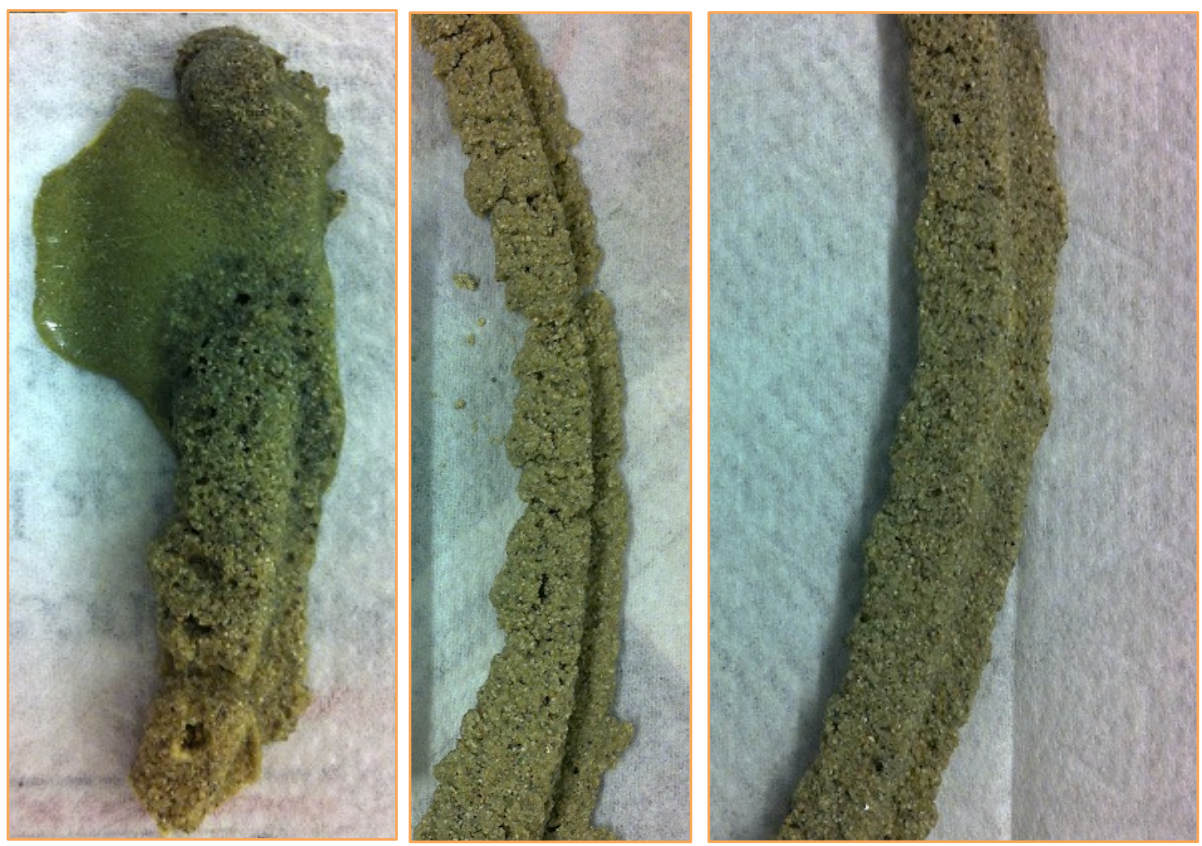

Figure 12. Extruded parts with 40\%, 30\% and 35\% sulfur concentration (left to right) that of the sintered cube in Toutanji's research. Sulfur concrete in this experiment is poorly pressed. Once a more powerful extrusion system is used to compact the sulfur concrete, the compressive strength is expected to increase significantly.

Experiments show that extruded sulfur concrete has promising properties, especially for lunar condition where gravity is $1 / 6$ of that of earth. Here are the main advantages:

1. Sulfur concrete gets melted at $120{ }^{\circ} \mathrm{C}$, and the specific heat is low, reducing the energy demand. In practical applications heating the mixture to $130{ }^{\circ} \mathrm{C}$ is sufficient for the process. 
2. Sulfur concrete cures very fast. Experiments show that in about 2 minutes after extrusion sulfur concrete becomes hard and can sustain multiple layers.

3. No waste material is generated because all the solid material could be fixed in the sulfur net.

4. Material is recyclable. The built part could be recycled by crushing it into small pieces or melted into paste. Material recycling is favored on lunar construction.

5. The interlayer binding is strong. By building parts in multilayers it is proven that the above layer could adhere to the layer underneath.

From the photos of the specimens it can be seen that the fabricated parts contain porosities in the inner structure, mainly caused by expanded air bubbles in the mixture; such phenomena will not exist in the lunar environment where there is no atmosphere. Compaction immediately after extrusion could also reduce the porosity.

\section{Lunar Regolith Sintering and Melting}

Planetary structures built with sulfur concrete will be fine if they are not exposed to heat higher than the melting point of sulfur. In certain conditions such as in critical areas of landing pads or under direct sunlight on the Moon the structure may experience heat with high temperature that could melt the sulfur concrete structure. Also, the strength of sulfur concrete may not be sufficient for some high load bearing sub-structures. Under such conditions molten regolith concrete will be a great feedstock candidate. Plain regolith, the only ingredient of such a concrete is also readily available almost everywhere on Moon and Mars.

Structures made with molten or sintered plain regolith have high compression strength. To sustain shock impact and tensile stresses, we have discovered that mixing metal powders before sintering significantly enhances the regolith tensile strength. We are also envisioning a variation of the $\mathrm{CC}$ method for sinteringbased fabrication. Numerous experiments have been carried out to study regolith sintering. The JSC-1A lunar simulant used in our experiments has been obtained from Orbital Technologies Corp. This regolith simulant is designed to be chemically similar to mare regolith. This simulant has a grain size smaller than $1 \mathrm{~mm}$, and melts at $1100-1125^{\circ} \mathrm{C}$.

Lunar regolith and its mixtures with copper and steel are manually compacted in graphite molds. Compacted regolith mixture is put into a ceramic furnace (CeramPress Qex Porcelain and Pressing Furnace). The sintering temperature ranges from $975^{\circ} \mathrm{C}$ to $1100{ }^{\circ} \mathrm{C}$, lasting for 1 hour or 2 hours, in a vacuum condition of 1 torr. Temperature rising rate is $25^{\circ} \mathrm{C} / \mathrm{min}$ starting from room temperature, and cooling rate to room temperature is decided by heat conduction to the platform in the same

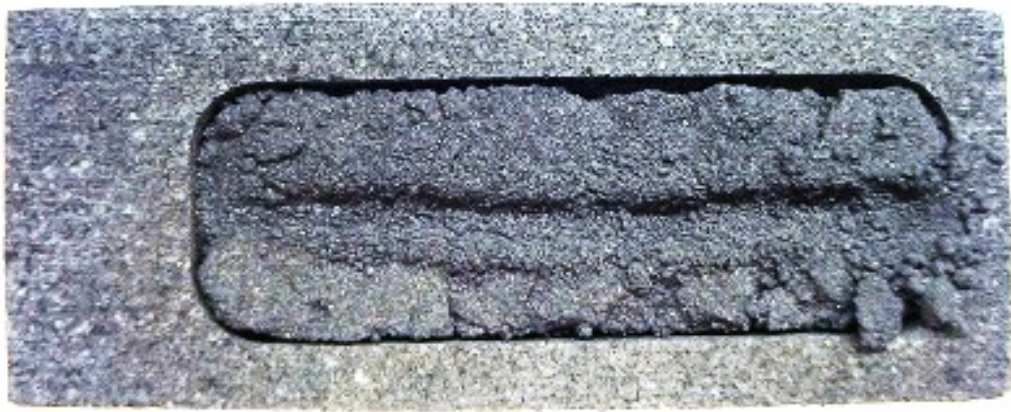
vacuum condition. The mold is $5.08 \mathrm{~cm} * 1.65 \mathrm{~cm} * 0.76 \mathrm{~cm}(2$ inch*0.65inch*0.3inch).

Figure 13. Plain regolith sintered at $975^{\circ} \mathrm{C}$ for 1 hour 
Results: As the temperature increases from $975{ }^{\circ} \mathrm{C}$ to $1100{ }^{\circ} \mathrm{C}$, compression strength increases first and then falls down due to porosity near melting temperature. At $975^{\circ} \mathrm{C}$, regolith barely sinters, there is almost no shrinkage, and even a pencil tip could brush off the cooled block, as shown in Figure 13. For plain regolith sintering as shown in Figure 6 , from $975^{\circ} \mathrm{C}$ to $1025^{\circ} \mathrm{C}$ the compression strength of sintered plain regolith increases and then drops down after $1050{ }^{\circ} \mathrm{C}$. The compressive strength at $975{ }^{\circ} \mathrm{C}$ for sintered parts is denoted as 0 . At $1000{ }^{\circ} \mathrm{C}$, increasing sintering temperature to 2 hours only slightly increases the compressive strength from $6.83 \mathrm{MPa}(991 \mathrm{psi})$ to $10.34 \mathrm{MPa}(1500 \mathrm{psi})$. From $1000{ }^{\circ} \mathrm{C}$ to $1025{ }^{\circ} \mathrm{C}$ the strength increases rapidly to $36.20 \mathrm{MPa}(5250 \mathrm{psi})$ and $53.5 \mathrm{MPa}$ (7760 psi), respectively. At $1050{ }^{\circ} \mathrm{C}$, sintered block contains large pores, significantly reducing the compression strength. At $1110{ }^{\circ} \mathrm{C}$, regolith melts and the powder swells out of the molds. The final parts contain large voids, which are visible at the surface as shown in Figure 15.

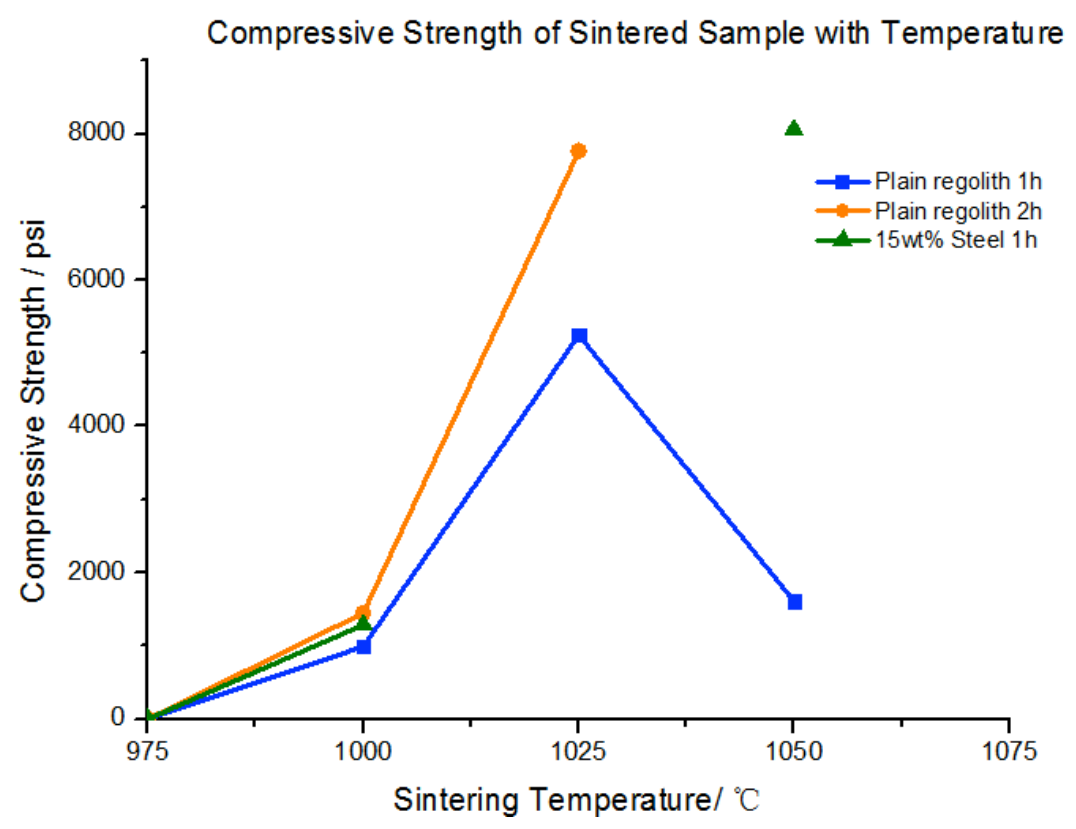

Figure 14. Compressive Strength of Sintered Sample with Temperature (The blue and orange dots denote plain regolith)

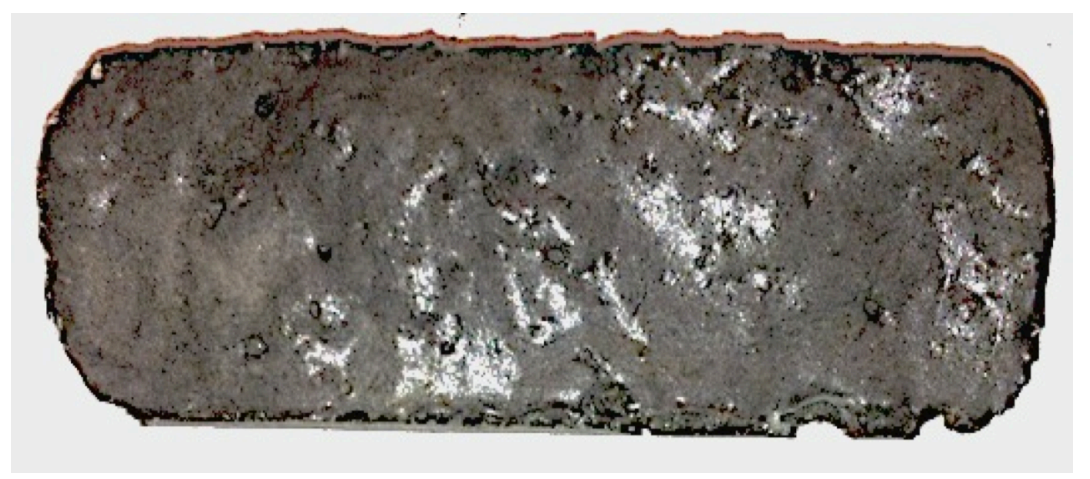

Figure 15. Plain regolith simulant sintered at $1100^{\circ} \mathrm{C}$ for 1 hour 
Adding steel powder into the regolith could increase the quality of sintered parts at high temperature. The steel powder used is SS316H of 325 mesh size. Without addition of steel powder, plain regolith will swell and voids appear inside the sintered parts. At the temperature of $1050{ }^{\circ} \mathrm{C}$ sintered blocks swell out of the molds as seen in Figure 16. With addition of steel powder with a weight ratio of 15\%, the mixture has a high compressive stress of $55.57 \mathrm{MPa}(8060 \mathrm{psi})$. The cracked sample after compression test also shows no visible voids in the sintered block.

Copper regolith mixture is also tested. Experiments show that copper could also increase the compressive strength but does not help at temperatures as high as $1050{ }^{\circ} \mathrm{C}$. Samples with copper also swell and contain vacancies inside.

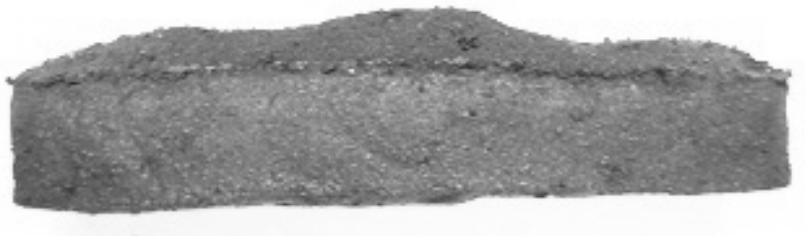

(a) Plain sintered regolith

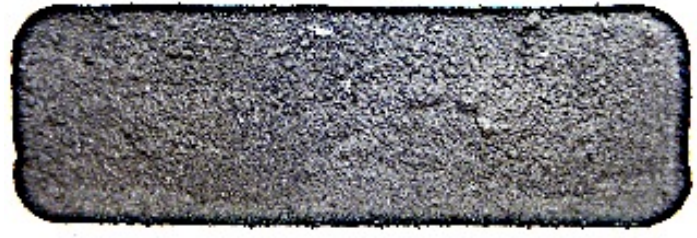

(b) Sintered regolith steel mixture

Figure 16. Plain regolith and regolith steel mixture sintered at $1050{ }^{\circ} \mathrm{C}$ for 1 hour

\section{Conclusion}

$\mathrm{CC}$ technology combined with sulfur concrete and regolith sintering has proven feasible in the lab setup prototype systems. This approach could significantly save the energy and time used for extraterrestrial construction, and liberates astronauts from the heavy and hazardous work of onsite construction.

Experiments have shown the feasibility of the CC technology with sulfur concrete. In-situ material of regolith and sulfur could be obtained with ease; saving transportation cost from the earth proves feasibility for space exploration. Sulfur concrete requires much less energy than competitive construction materials and is $100 \%$ recyclable. $\mathrm{CC}$ will be able to automatically build complex shape structures with sulfur concrete.

Compressive strength of sintered plain regolith and mixture could reach $55.16 \mathrm{MPa}$ (8000 psi), which is strong enough for building structures such as landing pads, blast walls and hangers. Sintering of regolith could be possibly used in two ways. First, regolith can be sintered with regular shapes like blocks and voussoirs, and regolith bricks. Faierson has showed that vousoirs with a compressive strength of 13.79 MPa (2000 psi) could sustain a self weight of $4259 \mathrm{~m}$ on the moon, since the dome structure is geometrically stable [3]. In this case regolith brick pavement might be combined with sulfur concrete extrusion. As sulfur concrete is extruded upon the previous layer of bricks, another layer of bricks may be paved upon it with a compression force. Such a combination could greatly speed up the construction rate and stronger buildings could be expected. Second, regolith sintering can be carried out on the construction site to yield the main construction material. A variation of the $\mathrm{CC}$ process may be used to deliver the regolith mix as a layer onto a selected area and keep it within the confines of three trowels (on sides and 
front) and expose the mix to sintering heat for certain time to complete the sintering process while slowly moving the delivery nozzle and trowels forward in a continuous sintering process.

Experiments are underway for layerwise fabrication using extrusion of molten regolith. These experiments will be best performed under vacuum as presence of air causes trapped gas expansion under extreme heat that result in voids in the extrudate. We plan to use the vacuum chamber at USC's Astronautics Department for future tests.

\section{SIMULATION PLAN}

At the outset, the team investigated the feasibility of executing a high fidelity simulation according to the NIAC Phase-I proposal. Cost of NASA assets and personnel clearly showed that it was not possible to do a meaningful demonstration under the available budgets and resources. Accordingly, the team turned to utilizing resources where valuable data could be gathered; further maturing technologies employing Contour Crafting in the laboratories at USC, depicting specific scenarios that would employ NASA assets that are undergoing extensive testing at D-RATS. Therefore, we did not divert much attention toward developing a detailed plan for a D-RATS simulation. However, it is the goal of this project to execute a simulation, once we have matured the technologies to the desired TRL and ORL levels. Following is the general outline for a proposed D-RATS simulation.

\section{Proposed Site}

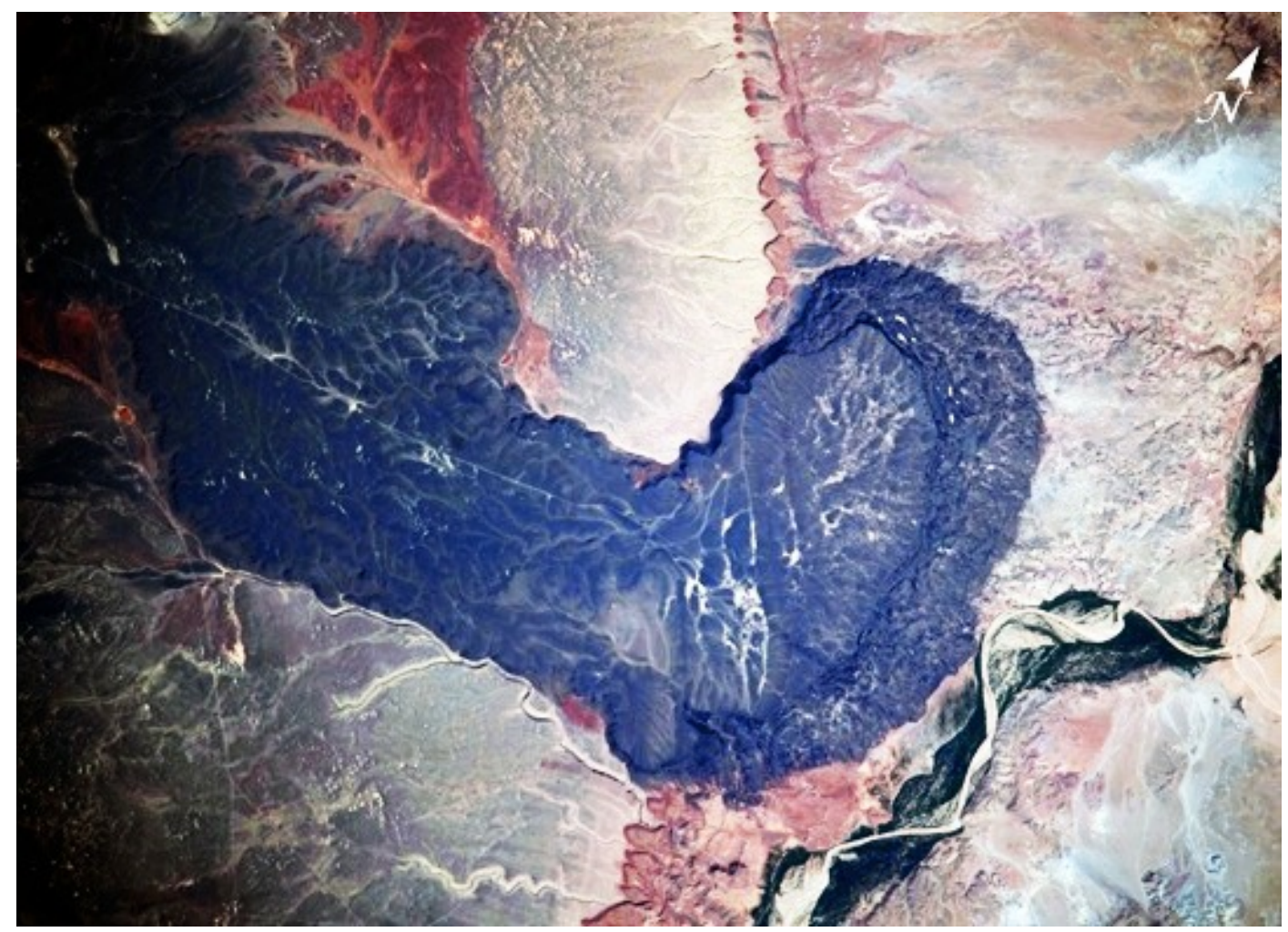

Figure 17. Black Point Lava Flow, AZ, seen from the air, is part of a private ranch leased by NASA in order to conduct the Desert Research and Technology Studies 
Black Point Lava Flow in Arizona is the site of the NASA D-RATS simulations. This desert region offers topographical terrain and features that approximate some pertinent extraterrestrial/lunar conditions. Several NASA technologies and systems are being field-tested there. It is our hope that when all the laboratory work has been satisfactorily completed at USC, that we will be able to transport a new Contour Crafting(CC) Machine, designed specifically for lunar infrastructure development, to the site and set up the demonstration in order to verify the merits and limitations of this technology when used in concert with other NASA assets in a synergetic manner.

\section{The Demonstration}

Using locally available materials, NASA assets depicted above, and the Contour Crafting machine, we hope to build :
i. $\quad$ a "to scale" landing pad
ii. Blast Apron
iii. A TBD length of soil stabilized and concrete overlaid road
iv. A dust-free platform for permanent habitat module assembly
v. Landing Pad Construction

Research into stabilized platforms, roads and paving suggests that the age-old, tried and tested Roman road construction methods offers a good candidate for a durable, resilient top for repeated lunar lander service including landings and liftoffs as well as repeated heavy cargo hauling across the surface.

A Roman road cross section, modified for lunar landing pad is depicted in Figure 18.

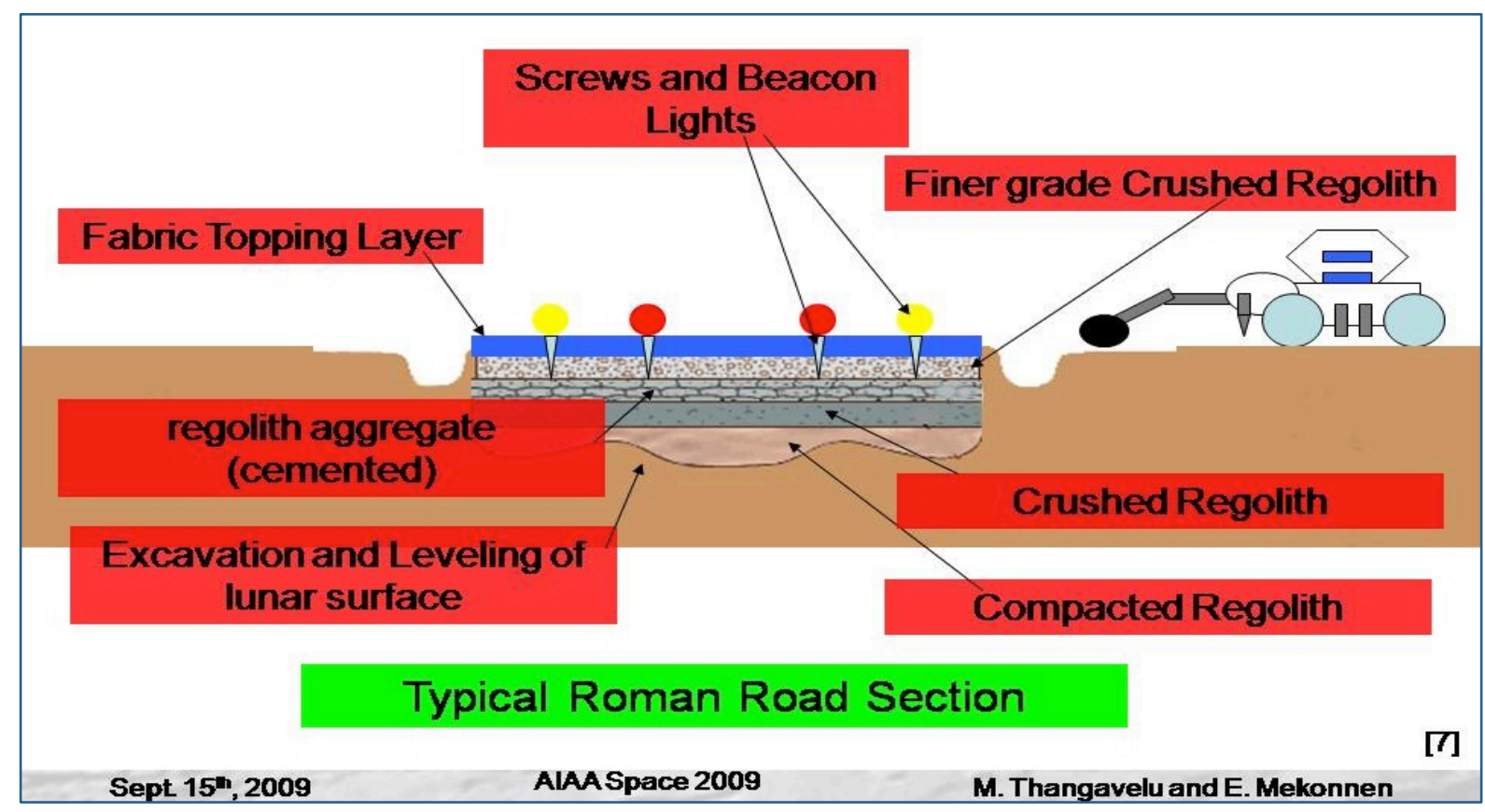

Figure 18. A typical cross section of a Roman road, modified for lunar landing pad. 
The simulation lunar landing pad is suggested to be approximately $30 \mathrm{~m}$ in diameter in order to set down the $14.5 \mathrm{~m}$ footprint of an Altair-class reference lander. A reference schematic is shown in Figure 19.

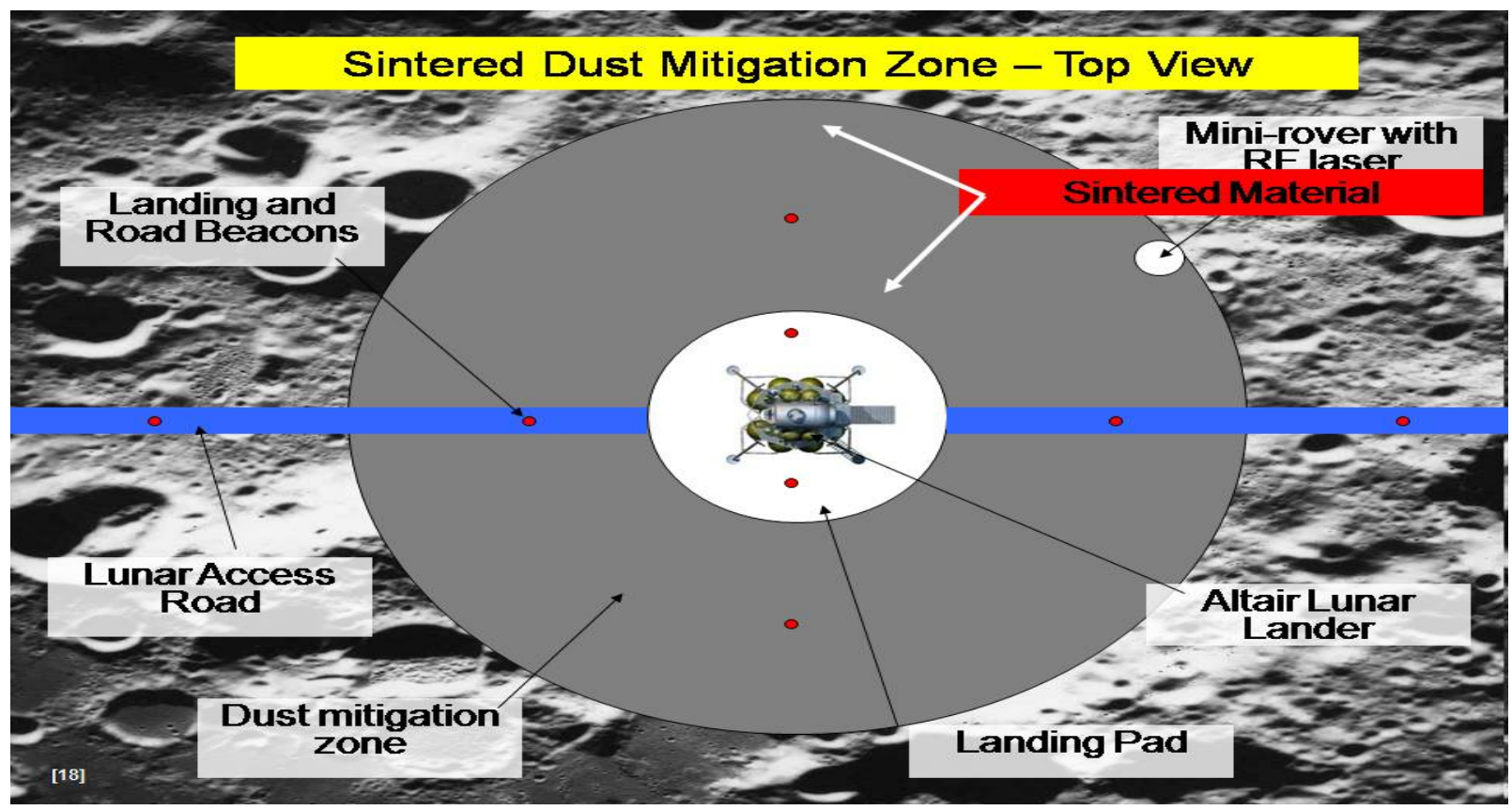

Figure 19. Schematic of the lunar landing pad and surrounding sintered regolith dust suppression region

First the site is selected. Selection criteria for demonstration are not as stringent as for a real lunar landing pad. The most important attribute is that it must be naturally level and workable to a desired depth of TBD feet.

We plan to use locally available rocks and earth. Using a commercial crusher, we will first collect, crush sort, grade and pile aggregates and fines in heaps close to the construction site to be used for this landing pad. Excavated materials including rocks and soil may also be heaped and used.

After marking the circumference perimeter, we will set up and employ the robotic CC machine gantry to clear and level this circular pad area. Then, we will excavate the earth within this perimeter using the same CC gantry. Once leveled, we will use a tamping attachment on the CC gantry to stabilize the surface.

This is followed by layers of aggregates, again poured in position by the CC machine. Each layer for TBD thickness is followed by tamping in order to compact the surface. This is followed by the TBD thick top coat concrete slurry delivered by the $\mathrm{CC}$ machine through a hopper system. As the concrete is extruded robotically, it is possible to vary the consistency, color and texture of the slurry, allowing the CC machine to vary the characteristics of the layer including thickness and strength, apply complex patterns and grooves as well as print markings directly onto the surface without the need for painting them on or applying them in a separate procedure later. 
An area surrounding the landing pad is further stabilized to prevent dust and debris effects during lunar lander descent and touchdown as well as during the initial liftoff period.Once the CC machine has completed the top coat, and peripheral activities concluded, the same CC gantry is used for the next demonstration.

\section{i. $\quad$ The Blast Apron}

In order to proactively stop any rocket exhaust ejecta and secondary effects such as hyper velocity debris from loose regolith in the area surrounding the landing pad from causing damage to habitats and other high value assets, a barrier is proposed. This element manifests as a wall of TBD height that is able to withstand the effects of the lander rocket plume as it touches down or lifts off the landing pad area.

The CC machine has already built sections of walls with intricate sections and built-in reinforcements. We expect to fully employ this capability to build a blast wall of TBD curvature and height and thickness adjacent to the landing pad.

The wall is designed in such a way as to be able to accommodate a service and storage area on the backside that is fully protected from the blast effects incurred during the lunar landing and lift off operations.

We also note that a blast wall can be an impediment and a flight safety risk in case of an uncontrolled landing. So, we have also looked at designs to avoid a raised feature that is depicted as an alternate configuration in Fig 20.

\section{ii. The lunar road}

A connecting road between the landing pad and the habitat is needed in order to keep the lunar dust from hampering routine transportation of crew and cargo between the landing site and the habitat. This distance is considered to be between $3-5 \mathrm{~km}$ in most proposals to date.

A similar procedure as for the landing pad is adopted for building a simulated TBD length of lunar road.

iii. A dust-free lunar habitat platform

Since most of the routine chores of logistics and other scientific projects around the permanent habitat will occur in and around the habitat zone, it is important that the immediate vicinity around the zone be made dust-free. Several options exist including laying fabric, tiles, sintering and other chemical means of stabilization. However, these strategies tend to overlook the heavy duty service cycles for crew and vehicles in the vicinity.

It is important to build a solid platform that will provide the necessary stability for setting the modular elements of the habitat complex as well as for repeated crew and vehicular traffic.

Once again, we will employ the CC machine and follow the same steps as for the lunar landing pad, with appropriate adjustments to thickness of layers and top coats to build up this dust-free habitat platform.

A schematic representation of the landing pad, road and platform is shown in Figure 20. 


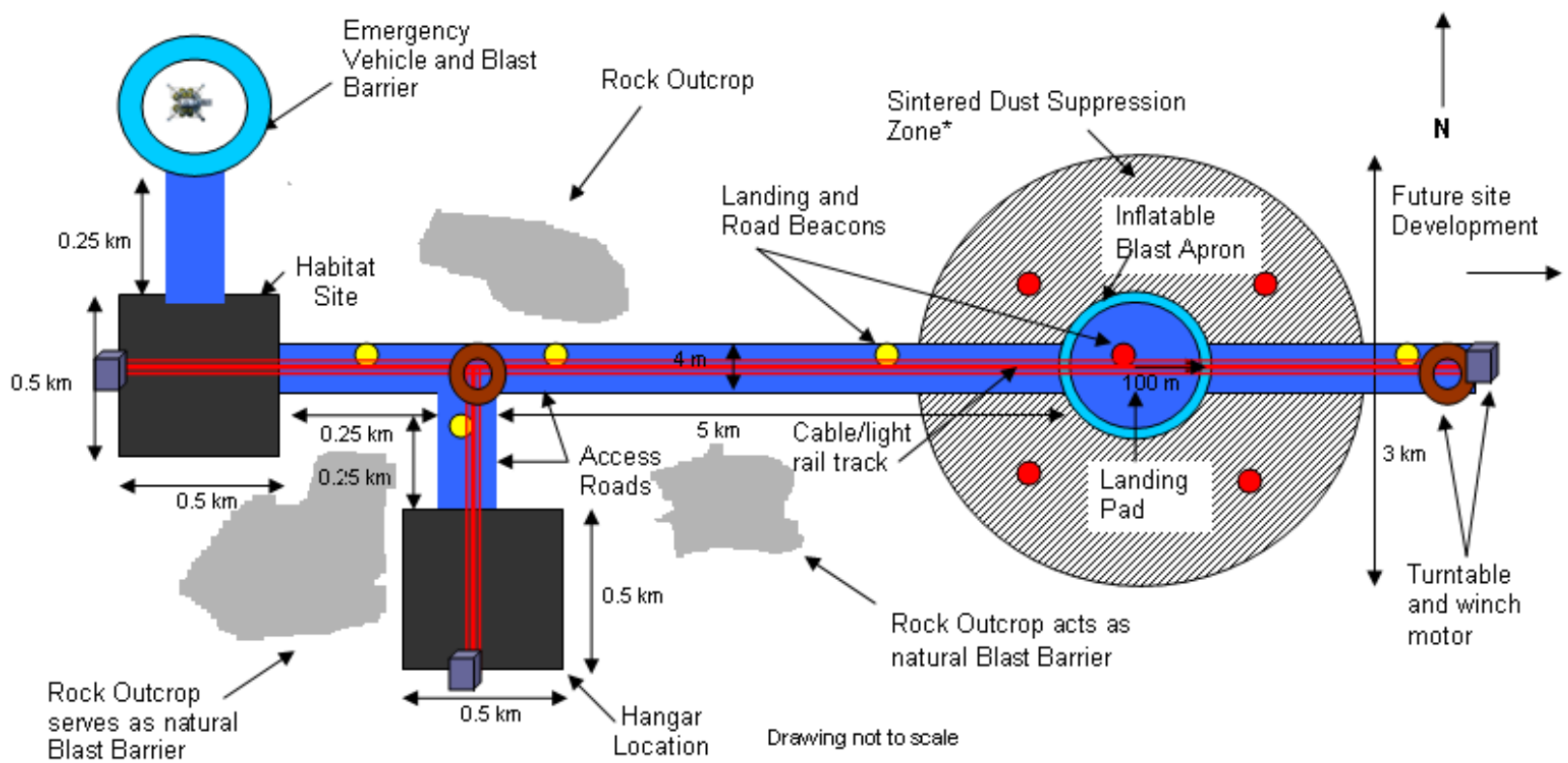

Fig 20. Schematic of a lunar landing pad, road and habitat and hangar platforms. A blast apron is alslo depicted to keep lander ejecta and debris from striking valuable assets including habitats in the vicinity. A light rail, powered by a winch and turntables to redirect landed payloads could be incorporated, if needed to handle heavy payloads and automated logistics service from landing pad to habitat.

\section{Real time Telerobotics and Co-Robotics Strategy for Simulation}

Unlike activities requiring command and control at interplanetary distances(it takes an EM signal several minutes to travel from Earth to Mars and back even in the most opportune orbital conjunction geometry), the lunar case offers unique possibilities different from the complete autonomy required for interplanetary guidance, navigation and control.

Robotic assembly of components offers promise for early stage lunar base infrastructure buildup activity including the construction of landing pads, roads and tracks, dust-free platforms as well as for unpressurized shelters protected from particle and thermal radiation and micrometeoritic bombardment.

Contour Crafting(CC) technology, a specialized, patented robotic structure building approach, with roots in the established field of Additive Manufacturing(AM) has been steadily advancing at the University of Southern California for the past decade [Khoshnevis et al., 2005, 2012].

Earth-based teleoperations may be combined synergistically with robotic $\mathrm{CC}$ technology to economically support tasks that can tolerate the 2.77 second round trip time delay introduced by the Earth-Moon distance.

Lunar surface based teleoperations, also referred to as real-time teleoperations, has been suggested to overcome this time-delay difficulty and well as accommodate certain communication system latencies and may also be necessary for timely feedback and response of certain critical, impromptu tasks that are not time-delay tolerant [Thangavelu 2008]. 
Astronauts operating from a lunar lander equipped with a telerobotic cabin may carry out such activities and may also supervise buildup employing CC machines, even allowing direct intervention through EVA to sort out aberrations or anomalies that are quite likely to occur during complex tasks that are part of project execution. A candidate architecture is the Cabin for Teleoperations C-TOPS [Thangavelu 2008].

Robots designed for specific functions also tend to be very quick and efficient in executing them, thereby compressing time schedules for project execution. They are very consistent in accomplishing assigned tasks and do not need recuperation periods between shifts. Regular maintenance is required but can be implemented even during work shifts. These factors make them attractive on the factory floor, compared to human workers.

The risk associated with fully robotic lunar assembly is the potential for schedule slippage or mission failure due to robot system malfunction or associated anomalies that cannot be resolved by Earth based teleoperations as shown in several studies like the FAIR-DART and the robotic Hubble Space Telescope mission [NASA 2004, SSB NRC 2005]. Adequate redundancy has been suggested to overcome this strategic deficiency and recent advances in robotics will overcome many of these obstacles as newer generations of robotic hardware and software arrive.

But for near term applications, real-time teleoperations by lunar surface based crew allows to correct this problem. However, when crew are introduced into the loop, safety and other critical mission constraints such as life support duration need to be taken into consideration [Thangavelu 2010].

Robots tend to perform as well or better than humans when the tasks and conditions can be reliably predicted. Humans are better-equipped to deal with the unexpected or abnormal. Human operators tend to fatigue rapidly when assigned repetitive tasks that robots carry out very efficiently. Therefore it is possible to carefully plan mission tasks and allocate those tasks that are best done by robots quickly and efficiently and assign others requiring impromptu feedback and dexterity to humans, thereby vastly improving mission performance.

\section{The Co-Robot Strategy}

It is possible to synergistically combine the telerobotic and real-time human supervision approach using the co-robot strategy. The co-robot or the robotic assistant is designed specifically to complement the astronaut team capabilities to carry out complex tasks, adopting an optimal, flexible, man-machine synergy model. Co-robots can help save time and resources while accomplishing mission tasks, sometimes requiring unrehearsed, impromptu or on-the-spot activities to correct deviations from routine and schedule.

A series of new initiatives by the current administration's recent report about US Robotics followed by an RFP called the National Robotics Initiative (NRI 2012) highlighted the importance of the co-robot strategy in the rapidly developing current context.

A co-robotic agent directly couples with humans to execute complex tasks, while removing humans from direct physical involvement on site. Autonomy is present a various levels within the command and control chain hierarchy, but the intent and goal execution is controlled by the human operator. Prime examples include the highly effective drones used in terrorism suppression, telemedicine surgery, 
advanced flight controls in aircraft such as the Boeing 787 and fighter jets, as well as certain controls in automobiles being routinely used today.

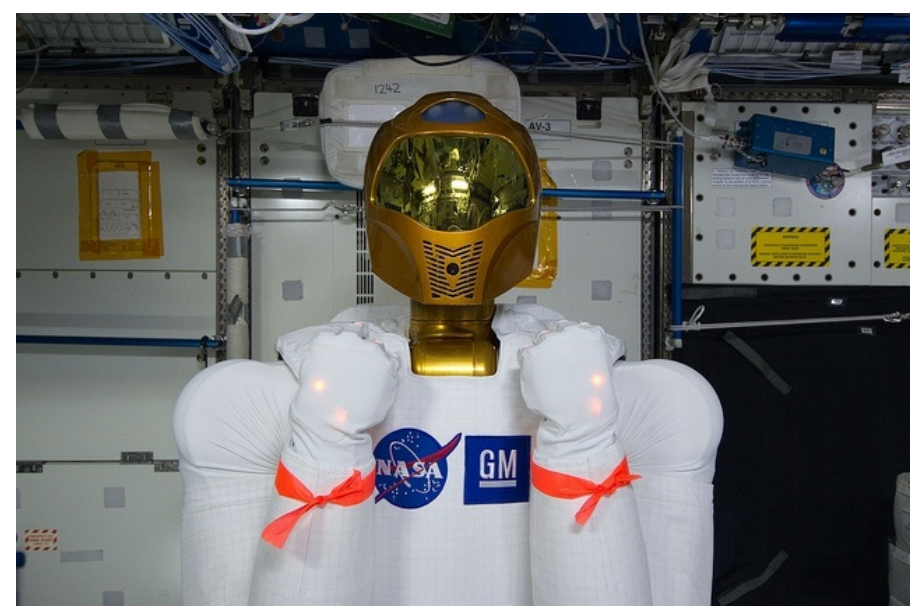

Figure 21. Robonaut 2 deployed on the ISS before arm activation

The co-robot, like the Robonaut 2 shown in Figure 21, now deployed and in service on the International Space Station (ISS), employs neural network algorithms to continually learn and hone tasks to assist the astronaut crew to safely and quickly accomplish mission tasks.

Of course, the proposed co-robot and teleoperations approach offers much promise for advance base deployment in hostile environments like those posed on the Martian satellites Phobos and Deimos to facilitate co-robotic base buildup activity on the Martian surface and here on Earth as well, opening up new opportunities for the design and building of complex urban development projects.

\section{NASA Robot Scaffolds of Interest for Grafting Co-Robotic CC Building System}

The current Contour Crafting system at USC has matured as a capable and versatile terrestrial automated building system. A working unit has been tested at NASA Marshall Spaceflight Center and several advanced versions are in development or under study at USC. Research underway is also looking for ways to adapt CC technology quickly and efficiently to support NASA missions. One way to achieve this goal is to graft the co-robot philosophy with CC technology to existing NASA robots that are being field tested and those which show promise for grafting CC technology.

There are a few important physical and operational parameters to pay attention to while selecting the appropriate robotic scaffold for space based CC technology. They include the ability of the scaffold to:

1. Be sturdy(while locked In position) under variety of terrain conditions

2. Be sturdy and still while the CC system is operating

3. Be operable in lunar extreme environment

4. Be able to carry and exchange variety of end effectors

5. Last but not the least, be co-robot activity friendly

Several NASA robots being field tested need to be investigated and empirically demonstrated in order to reliably ascertain which one is best suited for the CC building system. Proposed CC scaffolds include 
systems being tested at NASA D-RATS depicted in Figures $22 \mathrm{f}-\mathrm{d}$. (5h variations are not depicted in this document and will be included in the Phase 2 studies)

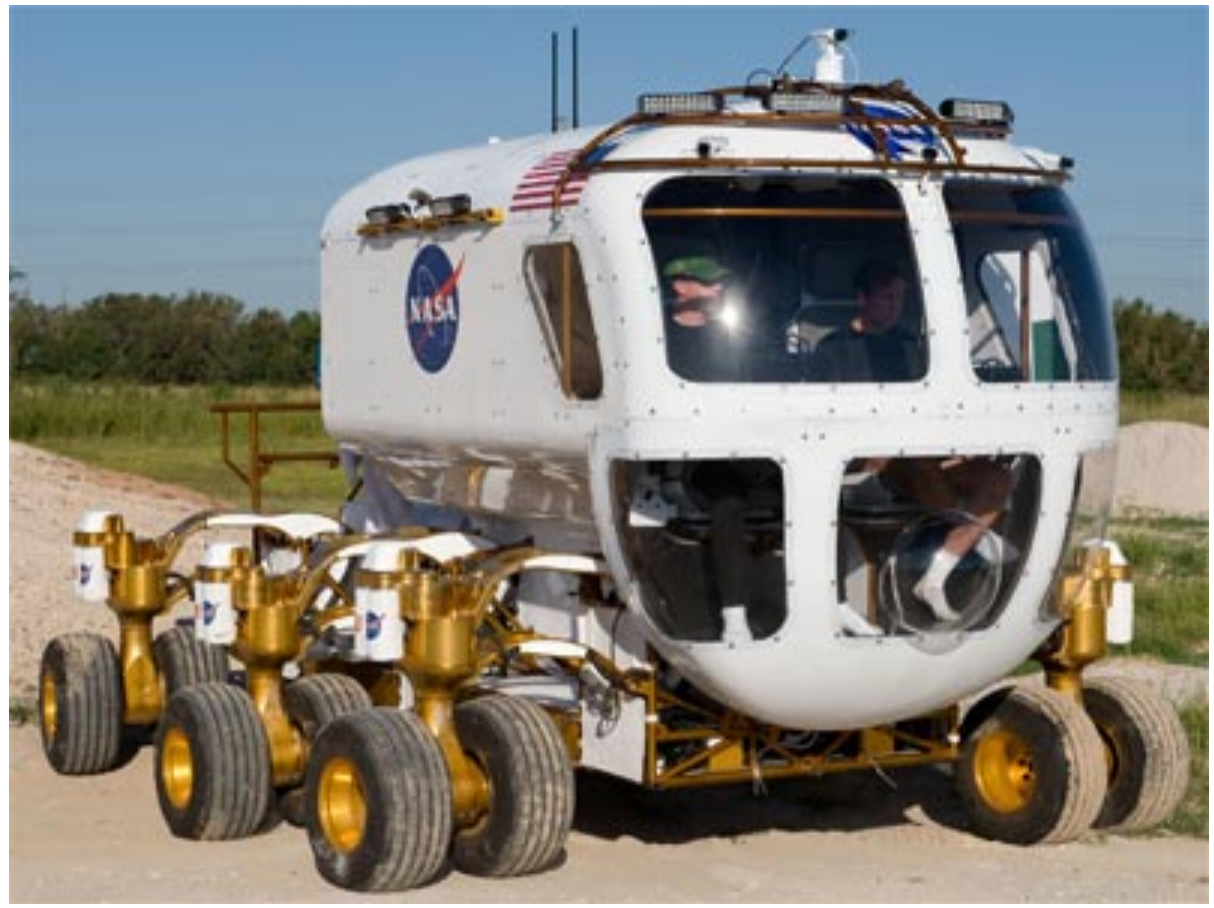

Figure 22. The NASA/GM lunar pressurized rover with trailer bed

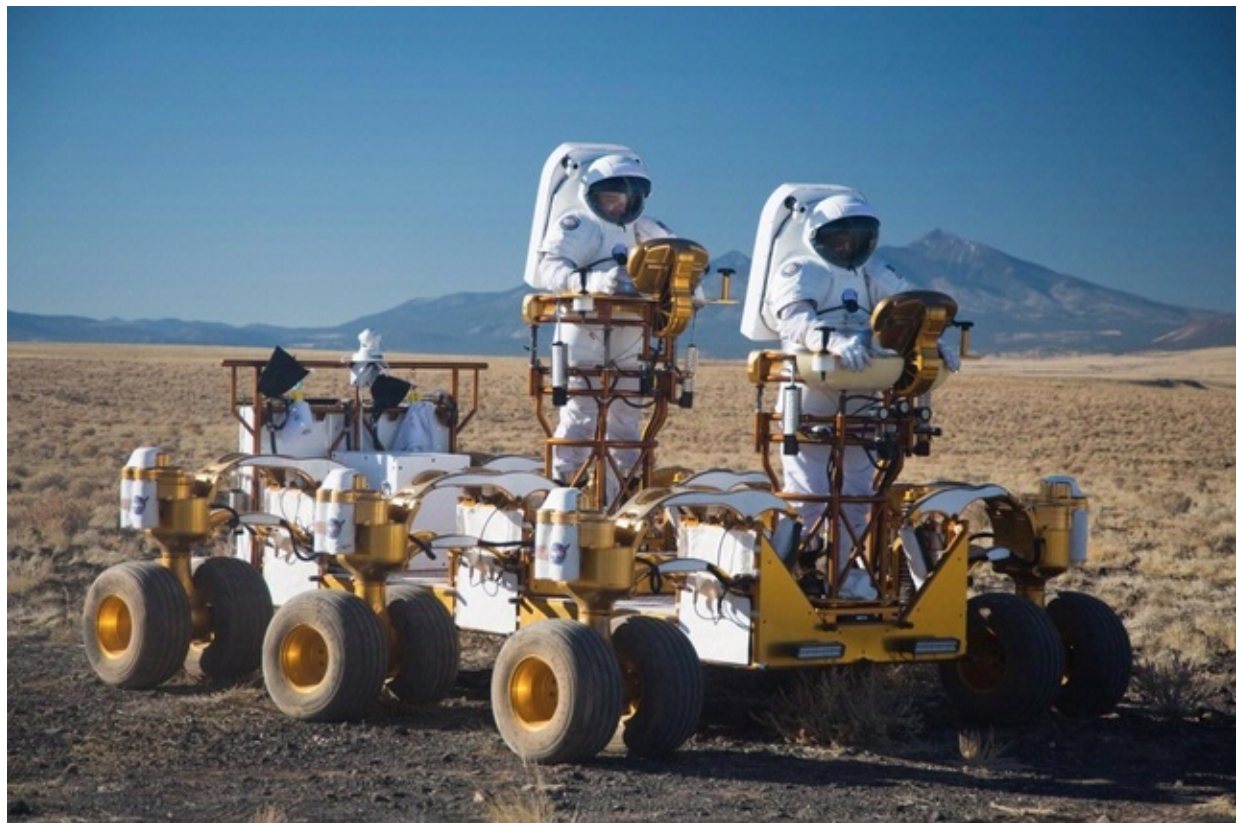

Figure 23.The unpressurized Chariot Chassis with appropriate CC systems 


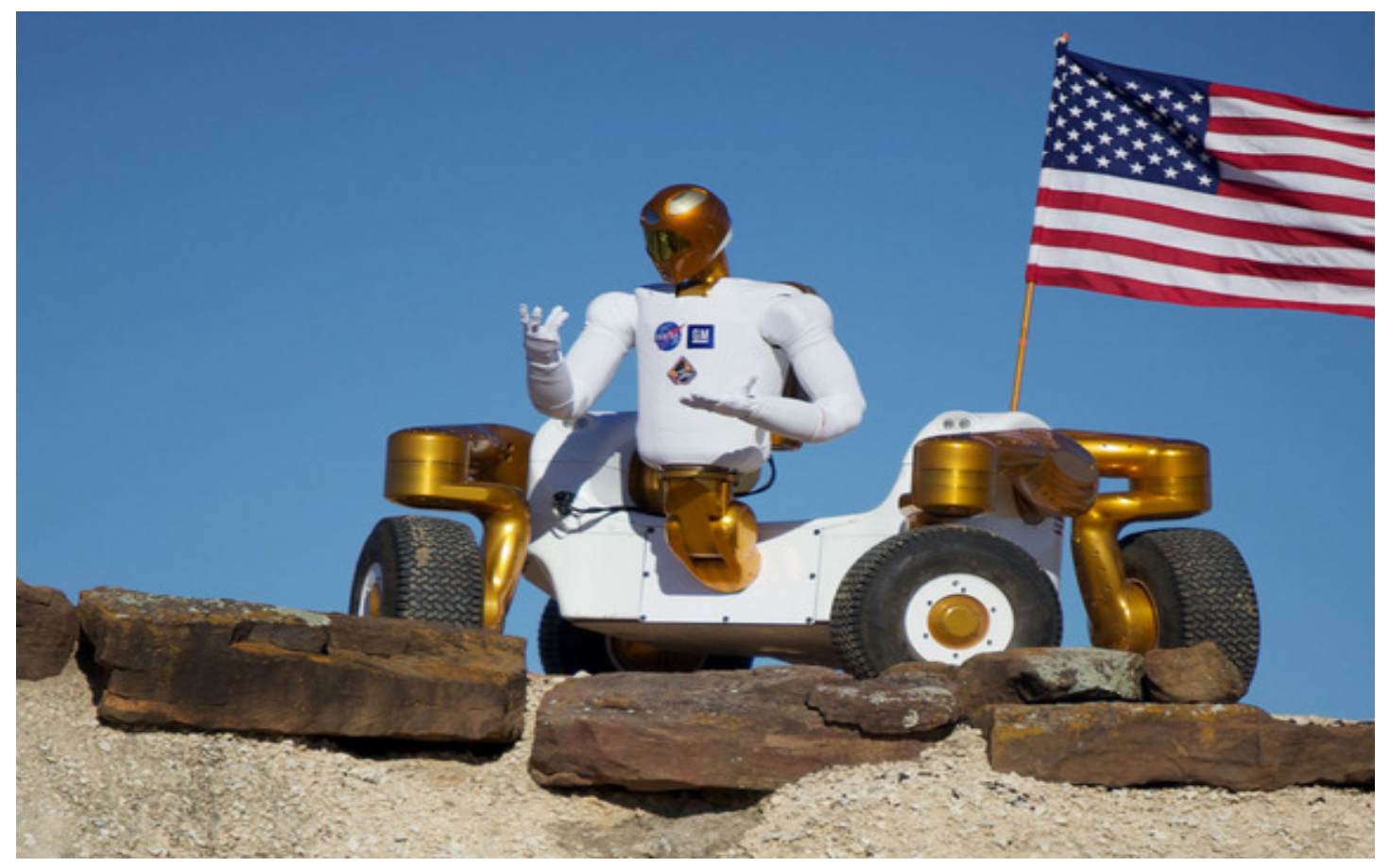

Figure 24. The small robotic Centaur

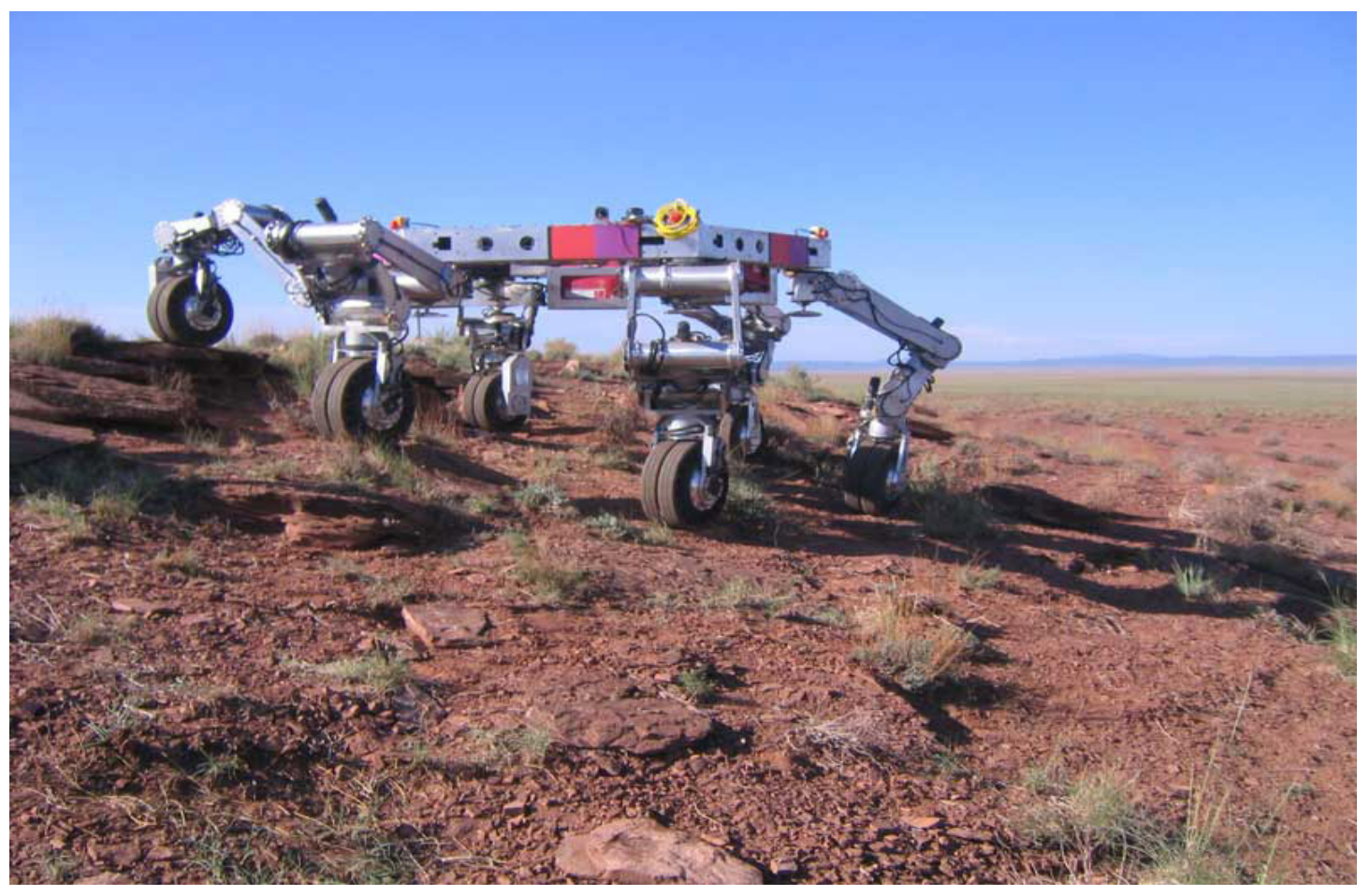

Figure 25. The ATHLETE chassis 
The principal task to be conducted on CC systems grafted to above NASA robotic scaffolds is to test which of these systems operate the best under co-robot environment in which they are assisted by astronauts and real time telerobotics.

\section{Figure of Merit - Comparison of Robotic vs. Co-Robotic buildup Strategy}

We should establish the critical numbers and experience that we hope to achieve from this simulation exercise. As with other D-RATS simulations, the operational experience gained from such an activity is invaluable as we hone the technologies, test and evolve the tools and systems needed to choreograph, execute and commission the above mentioned infrastructure elements, all in a smooth manner.

If resources allow, a specific figure of merit we wish to derive from this simulation is a comparison of effectiveness between a fully robotic strategy versus a co-robotic one for building up the above mentioned elements. We plan to integrate NASA reference missions wherever possible.

Figure of Merit numbers for each strategy will be attributed to parameters including:

1. Time to commission

2. MTBF of systems including CC machine

3. Energy usage

4. Change orders and schedule slippage management

5. Anomalies and resolution

6. Astronaut - Robot safety measures

\section{DEPLOYMENT PLAN}

Deployment of CC system for D-RATS simulation and for lunar commission are the two plans that need to be addressed. This section deals with the former and some suggestions regarding the latter.

\section{Deployment of CC system for D-RATS simulation}

The collapsible, deployable CC system is planned to be delivered to the D-RATS site by truck, carted from the lab at USC. Once on the site, it will be placed atop a simulated Altair class lander, along with other payloads. Currently we expect this shipping crate to be $5 \mathrm{~m} \mathrm{X} 3 \mathrm{~m} \mathrm{X} 2 \mathrm{~m}$ and in the $500 \mathrm{Kg}$ range. Such a payload is typically considered an auxiliary payload for the lander that is capable of landing approximately 40MT.

A lightweight crane that is deployed on or adjacent to the lander then removes the CC payload (possibly using a Dorsey crane) and places it directly on the site of operations, adjacent to the lander. Alternatively, a rover that is already commissioned would be used to carry the offloaded $\mathrm{CC}$ machine crate to the landing pad construction site.

Power: The first and foremost issue is power for the CC system, both for its mechanical and electrical sub-systems as well as for high bandwidth, high fidelity communications. We are currently looking at both solar panels that could be deployed on site or power from a separate TBD source, as has been employed in various D-RATS simulations. We expect the need for between $3 \mathrm{~kW}$ (for sulfur based 
concrete construction) to $7 \mathrm{KW}$ (for molten regolith construction) $\mathrm{kW}$ of peak power to operate the $\mathrm{CC}$ machine with all systems running.

Communications: Once the CC machine crate has been set in place, and power hooked up, the next task is to deploy the antenna and establish a communications link between the CC machine and mission control, either on site or at USC. We are looking toward incorporating the latest technologies to continually monitor CC machine activities including a variety of cameras and lighting elements so that the co-robotic operations crew can have the maximum situational awareness of the project execution during all phases of construction and commission.

Once communication channel is secured, commands from mission control will release the necessary latches on the crated CC machine, unfurl the solar arrays and deploy the folded gantry elements in a choreographed sequence of steps. After calibration, the simulation exercise will begin thereafter.

\section{Lunar Deployment of CC System}

Launch vehicles are being evolved all over the world to fill both governmental and commercial needs. Figure 26 shows the range of vehicles that are currently in service or being proposed.

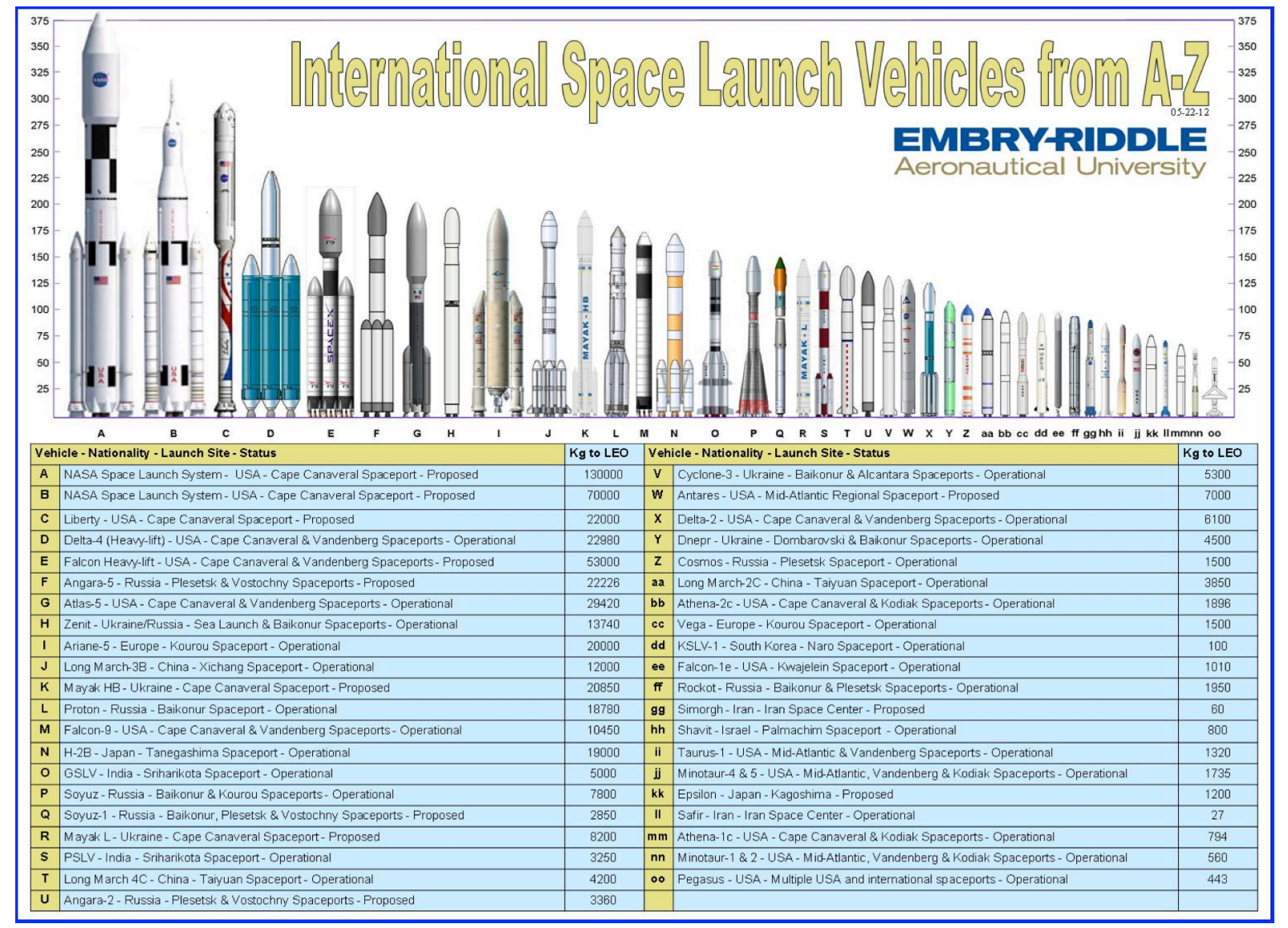

Figure 26. Launch vehicles big and small are able to carry a variety of payloads and execute a range of missions from LEO to GEO, from the Moon and Mars all the way to deploying spacecraft to the outer solar system and beyond. 
It is quite possible, given the span of time between the D-RATS simulation and real deployment on the Moon (perhaps 10 years), that several new developments will occur that allow more efficient transportation.

The current baseline depicts the Space Launch System (SLS) as the backbone for missions beyond Earth orbit. Several configurations and propulsion systems are being developed for the SLS. Configurations are shown in Figure 27. Figure 28 shows the launching vehicles by Space X, a private company that will also be able to deliver the CC system payload to Lunar surface.

Figures 29 and 30 show the payload fairing of a heavy lift launch vehicle. It is possible to stack eight school buses (120 MT) into the shroud of the SLS. A $5 \mathrm{~m} \mathrm{X} 3 \mathrm{~m}$ X 2m Contour Crafting system (inset in fairing) weighing only 500kg would just be an auxiliary payload on an SLS cargo payload headed for Moon. As Figure 31 illustrates, future Lunar landers are expected to be much larger than their predecessors with far more capacity for carrying large and heavy payload. And finally Figure 32 highlights potential candidate locations for Lunar settlement on the south pole region of Moon.

\section{SLS Vehicle Configurations}

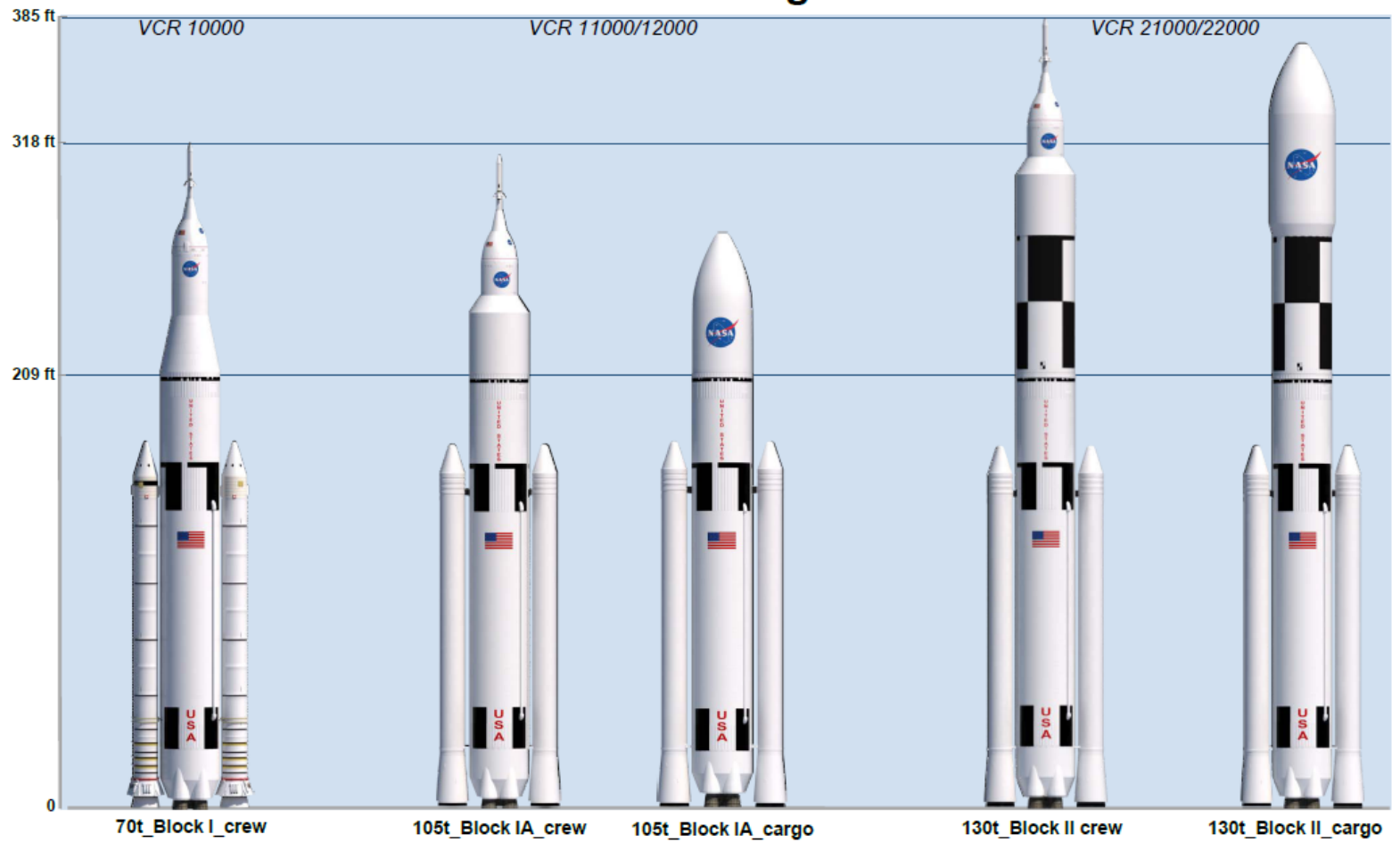

Fig 27. NASA's Space Launch System (SLS) with a payload capacity of between 70-130MT is currently base lined as the backbone for both crewed and cargo missions beyond Earth orbit. 


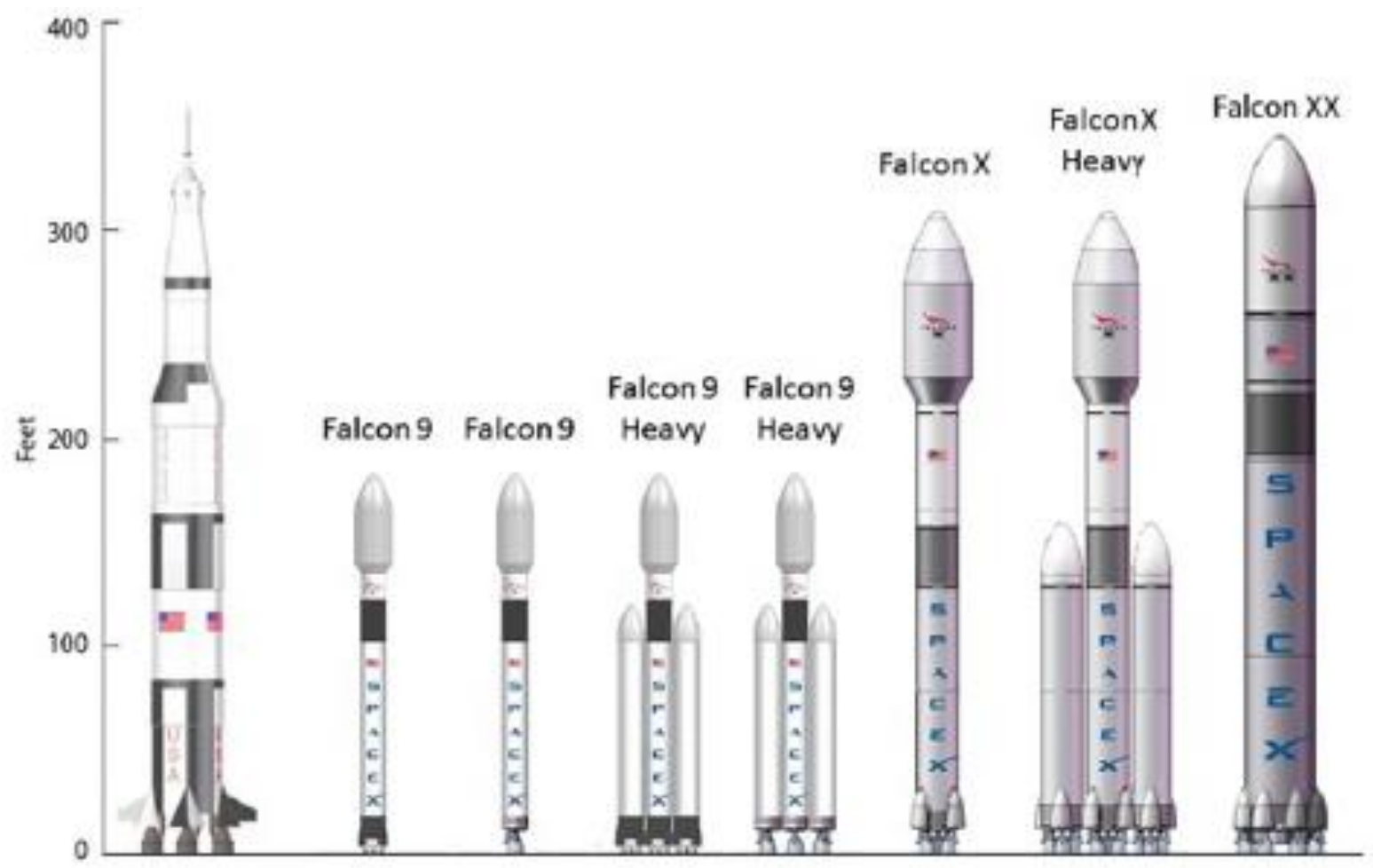

\begin{tabular}{|l|c|c|c|c|c|c|c|}
\hline VEHICLE & Falcon 9 & Falcon 9 & $\begin{array}{c}\text { Falcon 9 } \\
\text { Heavy }\end{array}$ & $\begin{array}{c}\text { Falcon 9 } \\
\text { Heavy }\end{array}$ & Falcon X & $\begin{array}{c}\text { Falcos X } \\
\text { Heary }\end{array}$ & Falcon XX \\
\hline 1st Stage Engines & $\begin{array}{c}\text { Merlin } \\
\text { ID }\end{array}$ & Merlin 2 & $\begin{array}{c}\text { Merlin } \\
10\end{array}$ & Merlin 2 & Merlin 2 & Merlin 2 & Merlin 2 \\
\hline Core Diameter (meters) & 3.6 & 3.6 & 3.6 & 3.6 & 6 & 6 & 10 \\
\hline Number of Cores & 1 & 1 & 3 & 3 & 1 & 3 & 1 \\
\hline Engines per Core & 9 & 1 & 9 & 1 & 3 & 3 & 6 \\
\hline $\begin{array}{l}\text { Engine Thrust (sea } \\
\text { level, lbf) }\end{array}$ & $120 \mathrm{k}$ & $1.2 \mathrm{M}$ & $120 \mathrm{k}$ & $1.2 \mathrm{M}$ & $1.2 \mathrm{M}$ & $1.2 \mathrm{M}$ & $1.7 \mathrm{M}$ \\
\hline $\begin{array}{l}\text { Total Lift-off Thrust } \\
\text { (Ibf) }\end{array}$ & $1.08 \mathrm{M}$ & $1.2 \mathrm{M}$ & $3.24 \mathrm{M}$ & $3.6 \mathrm{M}$ & $3.6 \mathrm{M}$ & $10.8 \mathrm{M}$ & $10.2 \mathrm{M}$ \\
\hline Engine Out Capablity? & Yes & No & Yes & No & Yes & Yes & Partial \\
\hline Mass to LEO (kg) & $10.5 \mathrm{k}$ & $11.5 \mathrm{k}$ & $32 \mathrm{k}$ & $3.4 \mathrm{k}$ & $38 \mathrm{k}$ & $1.25 \mathrm{k}$ & $1.40 \mathrm{k}$ \\
\hline
\end{tabular}

Figure 28. Private companies like Space X in the US are also developing heavy lift capability. The Falcon $X$ series is capable of landing large payloads on the Moon. 

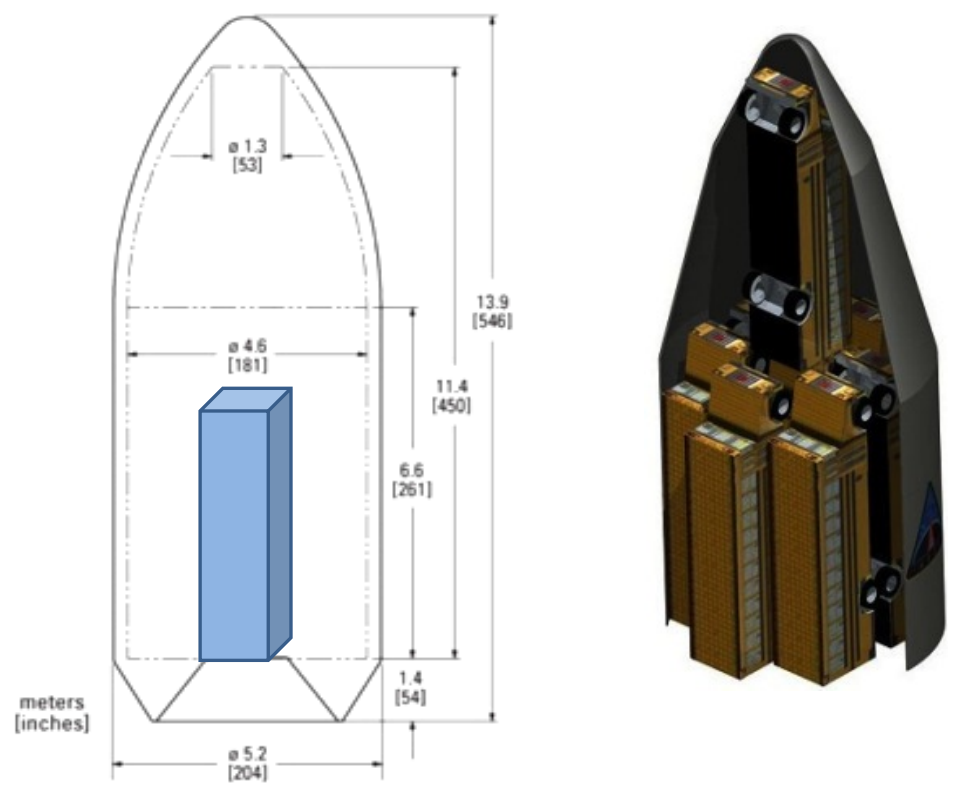

Figure 29. The cavernous payload fairing of heavy lift launch vehicles

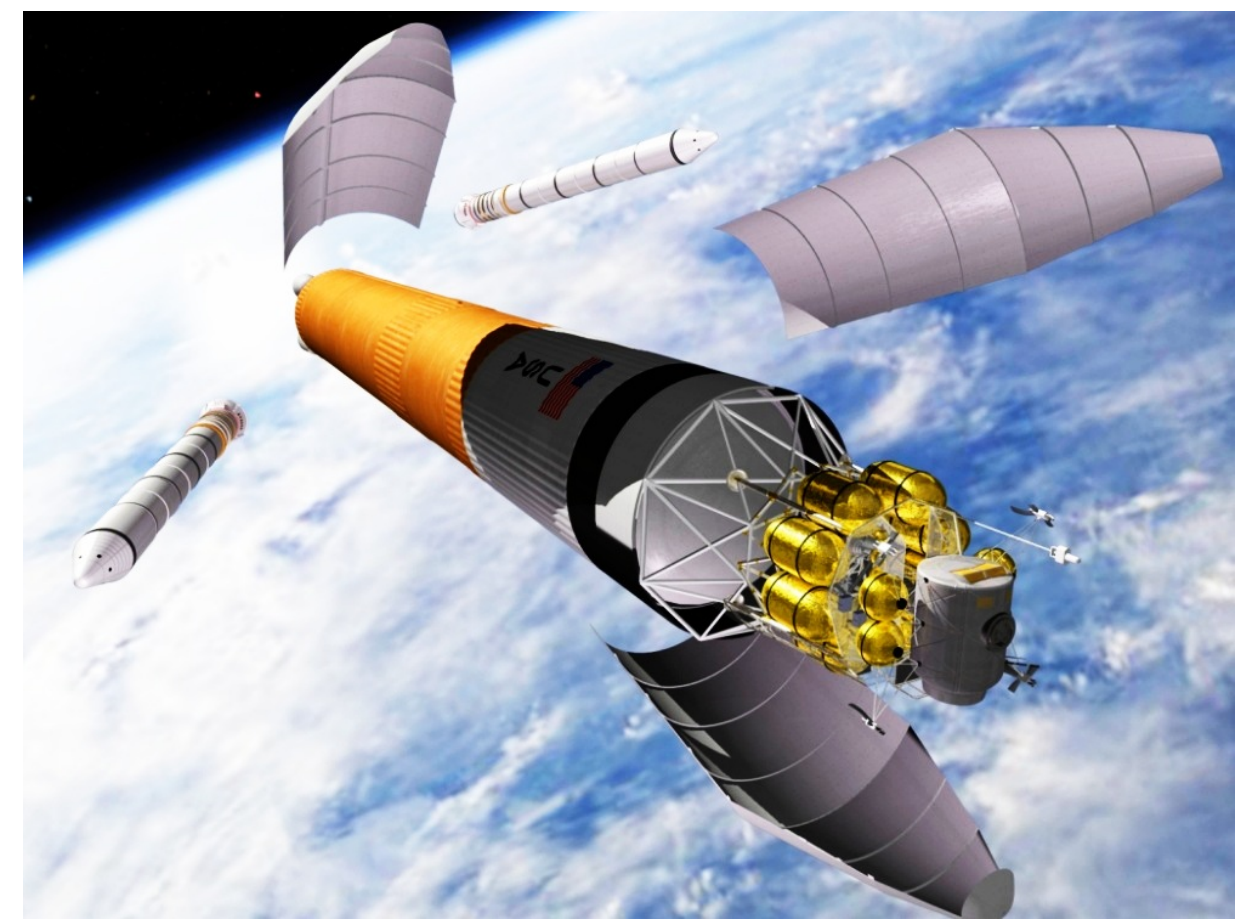

Figure 30. A heavy lift launch vehicle sheds its fairing after atmospheric phase of flight to expose its lunar lander payload on its way to the Moon 


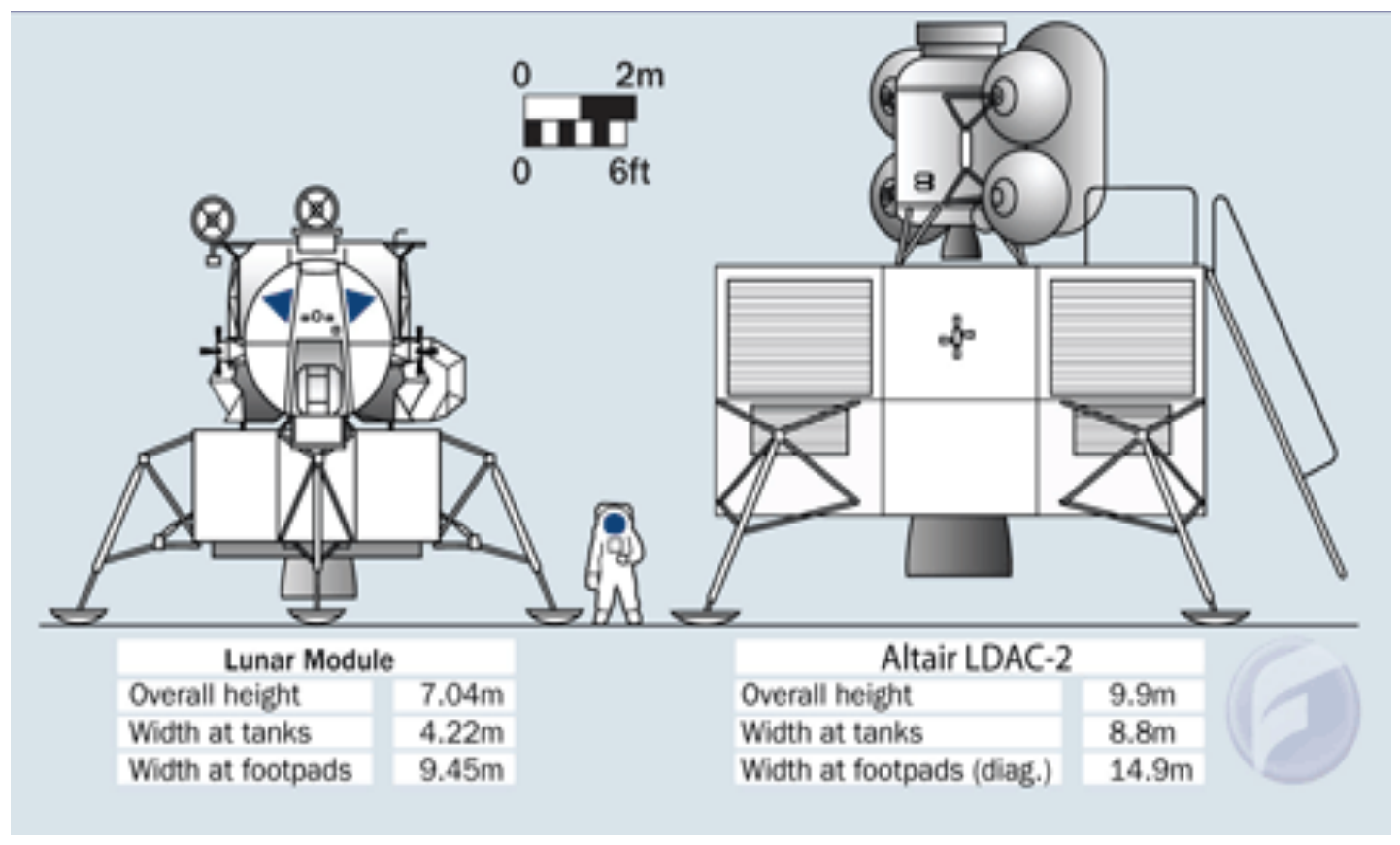

Figure 31. A size comparison of the Apollo era lunar lander and the reference Altair class lander that will launch atop the heavy lift launch vehicles like the SLS or the Falcon X series. The Apollo lander weighed approximately 14.5MT and the Altair class lander is proposed to weigh around 45MT.

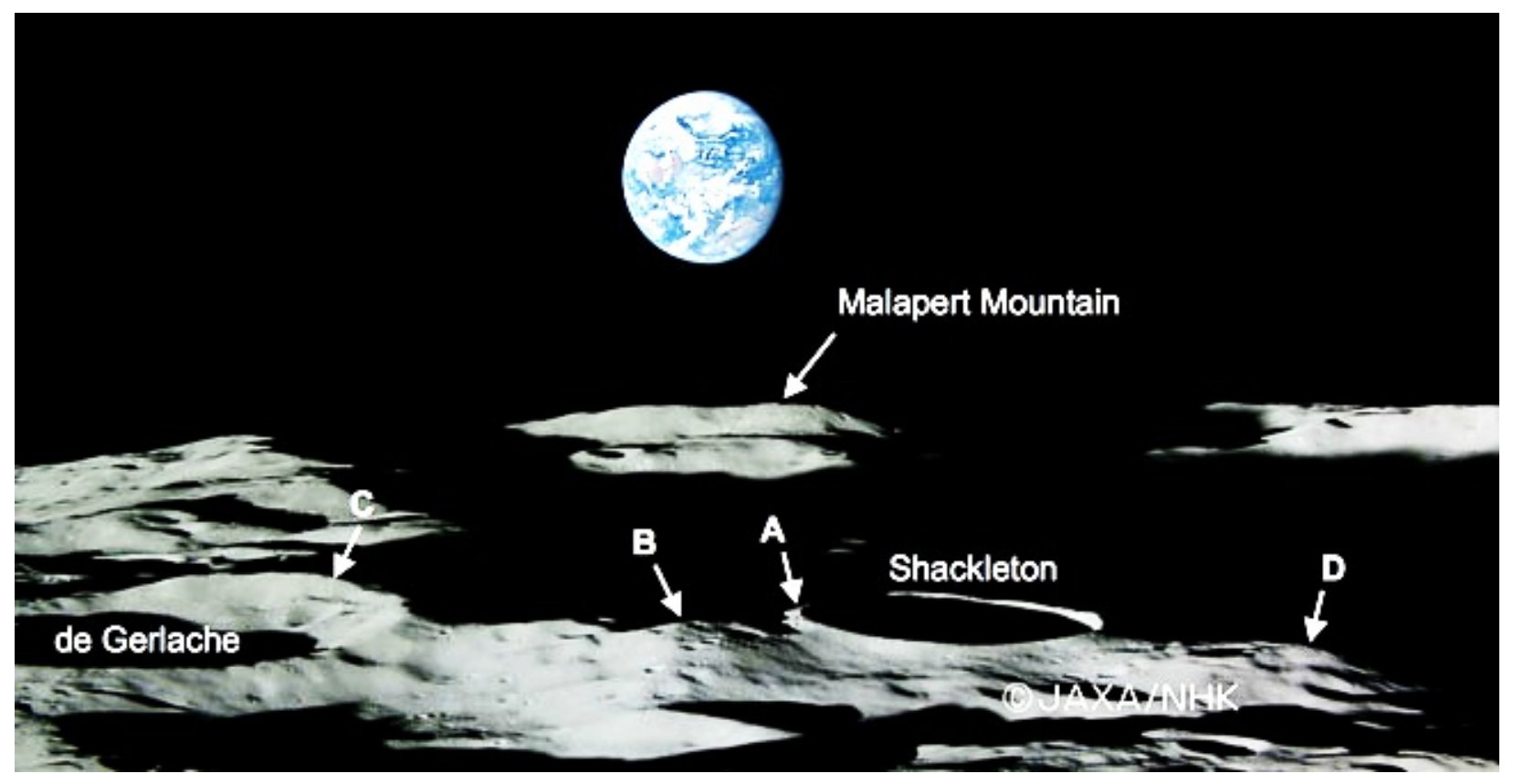

Figure 32. This image of the lunar south polar region highlighting the potential areas for setting up a lunar settlement. 


\section{EDUCATION AND OUTREACH}

As a background research exercise in support of our NIAC work we conducted a semester-long architectural design studio with USC postgraduate students of Architecture and Landscape Architecture. The studio was entitled, "Moon Studio," and was led by Neil Leach and Anders Carlson with substantial contributions from Madhu Thangavelu and Behrokh Khoshnevis. Students were required to research the Moon's environment and investigate various approaches to construction on the Moon. They were allowed to express their creativity but were required to follow a strict scientific method in their inquiry and to operate within the realistic constraints of the harsh moon environment. Examples of projects undertaken in this studio may be viewed online at uscmoonstudio.blogspot.com. One looked at sulfur harvesting and sulfur concrete construction, while another explored the potential of using GIS software to select the best sites for colonies on the moon and determine the optimized road paths between those sites. Other student research projects explored topics such as tourism, robotic colonies, ice harvesting, farming, lava tube settlements and other possible forms of development on the moon.

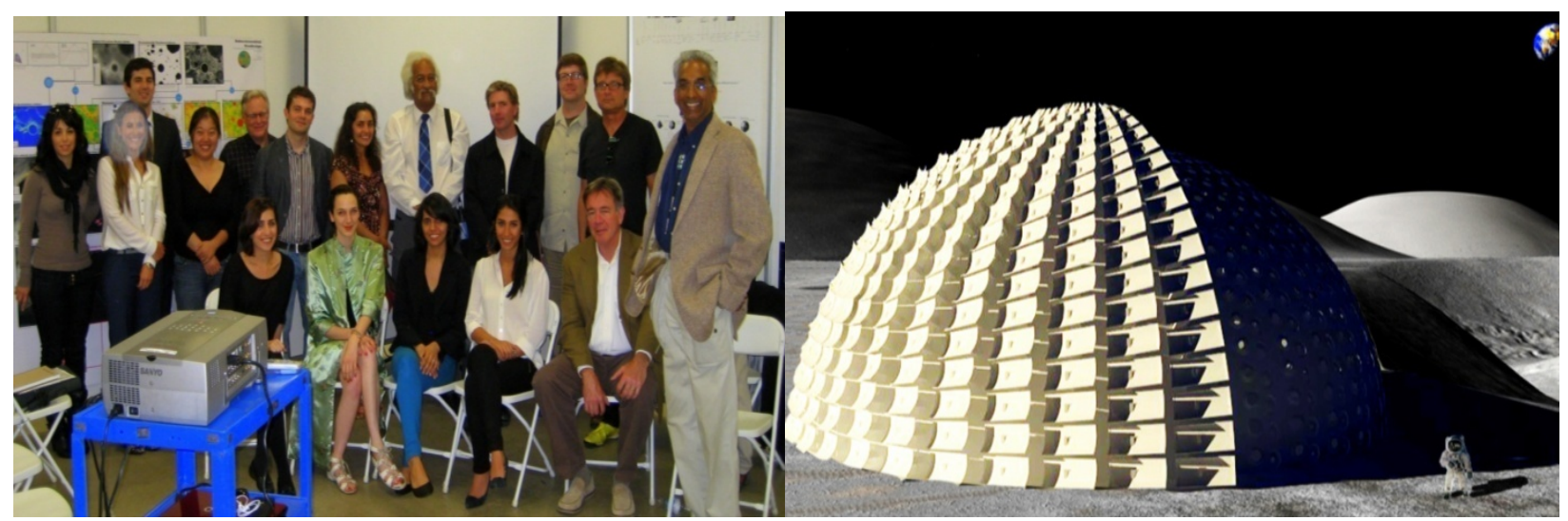

Figure 33. Left: Some of the Moon Studio students, faculty and critics Right: A sample Lunar structure conceived by Kiana Dolat.

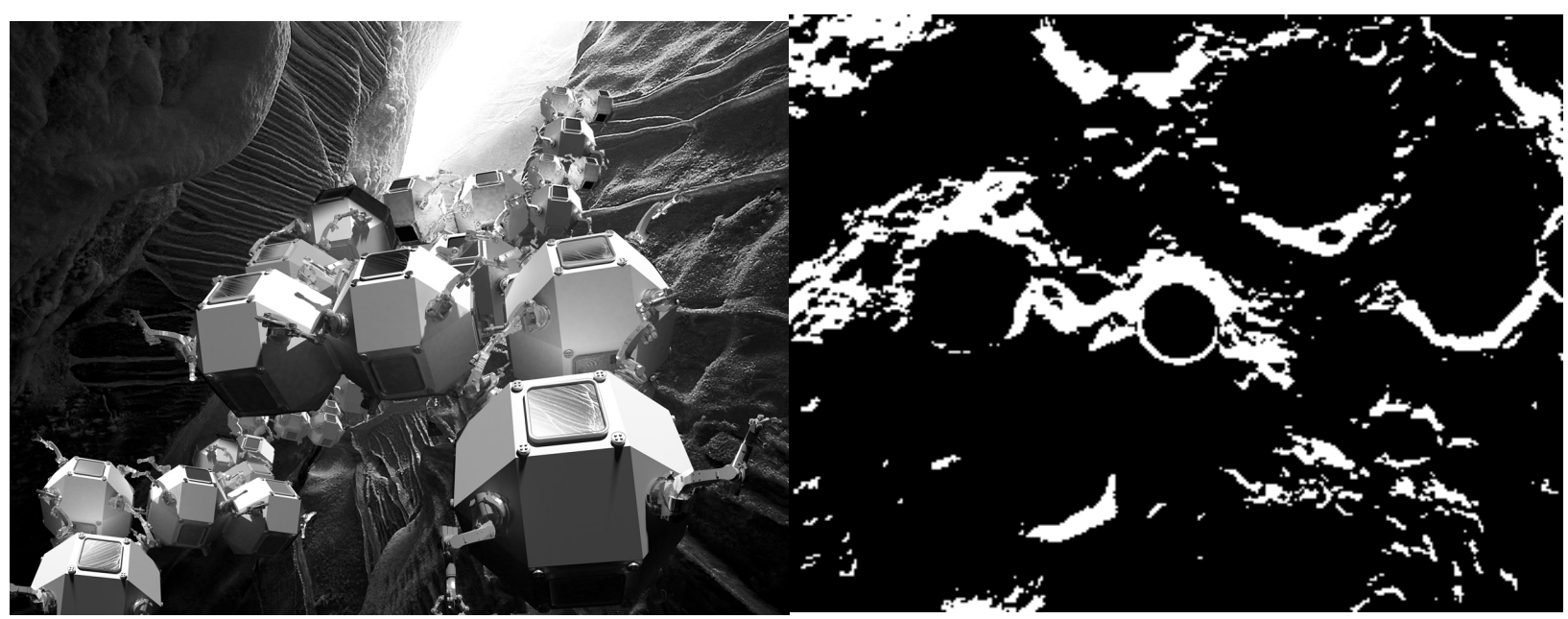

Figure 34. Left: Project for a mobile habitat by Behnaz Farahi. Right: GIS Study of the Moon by Lily Kerrigan

To coincide with the design studio a series of lectures were arranged: 'The Moon' by Dan Rasky, Director of the Space Portal, NASA; on 'Radiation and Planet Moon' by David Schrunk, co-author of the book, 
The Moon: Resources, Future Development and Settlement,; on 'The Mars Laboratory' by Anita Sengupta, JPL; on 'Space Tourism' by John Spencer, co-author of the book, Space Tourism: Do You Want to Go?, on 'Space Tourism'; on 'Psychological Factors in Space Habitats' by Harvey Wichman of the Aerospace Psychology Laboratory, Claremont Graduate University. Dr Buzz Aldrin, retired astronaut and the second man to walk on the Moon, also gave a presentation in the USC School of Astronautics that several students from the School of Architecture attended.

Our graduate research assistants have also received practical first class education about planetary conditions, materials, missions, and robotic fabrication technologies through their direct involvement in their assigned research duties. These students are always present and actively engaged in our routine NIAC project meetings.

The principle investigators working on this project have also given lectures about this project in other academic institutions and academic conferences including:

Behrokh Khoshnevis has given numerous talks, most notably his very popular TEDx, and talks at several universities (including Harvard on July 12) on the subject of Contour Crafting always dedicating a section on this NIAC project.

Madhu Thangavelu, 'Architectural Concepts employing Co-Robot Strategy and Contour Crafting Technologies for Lunar Settlement Infrastructure Development', AIAA Space 2012 Conference, Pasadena, 13 September 2012

Neil Leach, 'Desiring Machines', Keynote Address, DeSForM: Meaning, Matter, Making, Victoria University of Wellington, New Zealand, 18-20 April 2012

Neil Leach, 'Machinic Processes', Keynote Address, Architecture, Education, Practice and Research, 2012, School of Architecture, Bangladesh University of Engineering and Techniology, Dhaka, Bangladesh, 2-4 February 2012

Neil Leach, Lectures at: Dessau Institute of Architecture, Dessau, Germany; IaaC School of Architecture, Barcelona, Spain; School of Architecture, Technical University of Novi Sad, Novi Sad, Serbia; School of Architecture, Tsinghua University, Beijing, China; and the College of Architecture and Urban Planning, Tongji University, Shanghai, China.

\section{PUBLICATIONS AND PUBLICITY}

\section{Publication}

Our team has been active in publication of our NIAC project related work. In addition to the following articles we are currently working on a number of research papers that will be submitted within the coming year.

- Behrokh Khoshnevis, Anders Carlson, Neil Leach, Madhu Thangavelu Contour Crafting Simulation Plan for Lunar Settlement Infrastructure Buildip, ASCE Earth and Space Conference, Pasadena, April 15-18, 2012.

- Behrokh Khoshnevis, Anders Carlson, Neil Leach, Madhu Thangavelu, 'Robotic Construction on the Moon: The Potential of Contour Crafting, Urbanism and Architecture, Harbin, China, September 2012, No. 96, pp. 40-48. 
- Neil Leach, 'Machinic Processes' (USC Moon Studio), Urbanism and Architecture, Harbin, China, September 2012, No. 96, pp. 33-39.

- Behrokh Khoshnevis, Neil Leach, 'Contour Crafting: A Revolution in Concrete Construction' in Philip Yuan, Neil Leach (eds.), Fabricating the Future, Shanghai: Tongji University Press, 2012, pp. 100-105.

- Behrokh Khoshnevis, Anders Carlson, Neil Leach, Madhu Thangavelu, 'Robotic Construction by Contour Crafting: The Case of Lunar Construction', International Journal of Architectural Computing (forthcoming)

- Behrokh Khoshnevis and Jing Zhang, "Extraterrestrial construction using Contour Crafting,"Proceedings volume of the 2012 SFF Symposium, Austin, TX, August 2012.

\section{Publicity}

Our NIAC project has had an unusual publicity:

- A Google search of NASA+Khoshnevis yields about 40,000 entries. A random review of those entries indicates that at least two thirds of them relate to our NIAC project.

- The TEDx talk given by the PI of this project has attracted about 600,000 viewers. Several organizations, companies and individuals contacted us about our NIAC project. One company that approached us is Space X, which is very serious about getting engaged in our NIAC supported project with the aim of focusing on Martian construction. Space $\mathrm{X}$ is willing to consider joining NASA in this effort or independently pursue the Martian construction project.

- Numerous media outfits such as Washington Post and Popular Science have written articles on our project. We have been contacted by at least twenty journalists from around the world for articles on our NIAC project.

- The Discovery Science channel just interviewed us specifically for our NIAC project. The interview will appear in a dedicated program on space technologies and segments of the interview will be used in different programs.

\section{FUTURE WORK / IMPACT}

We feel fortunate to have received the NIAC Phase-II grant which has given us the opportunity to continue to work on this exciting and rewarding project. We have numerous new ideas that we would like to attempt and implement in the course of our current NIAC project. In addition to research that will advance the maturity of the proposed architecture, we anticipate other divisions of NASA to be interested in expanding the robotic construction methods that we will develop to build other types of ISRU based components beyond basic infrastructure. Robotic construction technologies could build tools, other robots, scientific equipment and many other objects that can be formed from excavated and processed extraterrestrial materials. We also anticipate major contributions by robotics and co-robotics researchers at NASA divisions to integrate our proven fabrication technologies with space-worthy advanced class of NASA robotics hardware and intelligent software. Once such integration materializes exciting demonstrations at D-RATS will be performed and following successful demonstration and refinement the ultimate dream of actual Lunar settlement construction will be realized. 
A robotic construction system can also provide tremendous benefits for human habitation on Earth. Construction is the last frontier of human endeavor to be automated. Automated building technologies will revolutionize the way structures are built on Earth, in dense urban environments, in difficult-to-build and difficult-to-service sites, or in remote and hostile regions of the globe. The technologies under development by our group have the potential to simplify construction logistics, reduce the need for hard physical labor by assigning humans to a strictly supervisory role, eliminate issues relating to human safety, and produce intricate and aesthetically refined designs and structures at significantly reduced construction cost. Space architecture in general and Lunar and Martian structures in particular will also provide a rich new aesthetic vocabulary for architects to employ in the design and creation of buildings that employ high technology and building information modeling that is vital for optimizing use of materials and energy that is critical to building economics. We anticipate this NIAC initiated endeavor to ultimately lead to revolutionizing construction on our planet and significantly impacting the quality of life for billions of people and improving the state of the earth environment.

The recently published "Roadmap for US Robotics" has identified several key areas and related enabling technologies for co-robotics which will result in US economic expansion. Robotic construction falls into two categories of manufacturing and professional services identified in that Roadmap. The economics of the proposed approach will enable the construction of durable, low-cost housing in the US and worldwide, and can enable much faster disaster recovery. Replacing human workers with robots on construction sites will reduce the injuries and fatalities of construction, which has long been recognized as the most hazardous occupation. Some of the specific proposed research modules will also have broad impacts. For example, construction using sand and without the use of water would be extremely useful for dry climates, and the work on radiation shielding may lead to terrestrial benefits such as improved and more economical shielding at nuclear power plants and nuclear waste storage sites. Student involvement will develop uniquely experienced future US construction robotic engineers and researchers. 


\section{REFERENCES}

Alexander, J.P., Roberds, W.M., and Scott, R.F. , "Soil Erosion by Landing Rockets, Hayes International Corporation," Engineering Report No. 1301, July 15, 1966 (NASA/MSC Contract NAS94825).

Bodiford, M.P. et al., (2005) “Are We There Yet?...Developing In Situ Fabrication and Repair(ISFR)Technologies to Explore and Live on the Moon and Mars", proceedings of the $1^{\text {st }}$ Space Exploration Conference: Continuing the Voyage of Discovery, edited by NASA MSFC, AIAA-20052624.

Cooper, Ken et al., (2007)Rapid Prototyping: Layered Metals Fabrication Technology Development for Support of Lunar Exploration at NASA/MSFC, Appendix V pp513-524, The Moon, Resources Future Development and Settlement, ISBN978-0-387-36055-3, Springer/Praxis publishers, UK.

Duke M.B.(1998)Editor Workshop on Using IN SITU Resources for Construction of Planetary Outposts / - 1998.57p. - (LPI Technical Report Number 98-01).

Doggett, William; Dorsey, John; Collins, Tim; King, Bruce; Mikulas, Martin,(2008) A Versatile Lifting Device for Lunar Surface Payload Handling, Inspection \& Regolith Transport Operations, SPACE TECHNOLOGY AND APPLICATIONS INTERNATIONAL FORUM-STAIF 2008: 12th Conference on Thermophysics Applications in Microgravity; 1st Symposium on Space Resource Utilization; 25th Symposium on Space Nuclear Power and Propulsion; 6th Conference on Human/Robotic Technology and the Vision for Space Exploration; 6th Symposium on Space Colonization; 5th Symposium on New Frontiers and Future Concept. AIP Conference Proceedings, Volume 969, pp. 792-808 (2008).

Eagle Engineering(1988) Lunar Base Launch and landing facility conceptual design . Report No.88-178, Contract NAS9-17878, March, 1988. $100 \mathrm{p}$

Eckart, Peter., (2006) The Lunar Base Handbook: An Introduction to Lunar Base Design, Development, and Operations, 2nd Edition. McGraw-Hill. 860 pages.

Eckart, Peter.,(1996)Spaceflight Life Support and Biospherics, Microcosm/Kluwer Publishers, ISBN 07923-3889-8

Eppler, D.(1992) http://www.lpi.usra.edu/lunar_resources/documents/ApolloRoboticPrcrsrs.pdf

Hogue, M., R. Mueller, P Hintze, L. Sibille, and D. Rasky, "Regolith-Drived Heat Shield for Planetary Body Entry and Descent System with In-Situ Fabrication", ASCE Earth \& Space Conference, Pasadena, CA, April 2012, pp 526-536.

Kerrigan, L (2012) USC Moon Studio, USC Internal report.

Khalili, E.N.,(1989)Lunar Structures Generated and Shielded with On Site Materials, Vol.2, No.3, ASCE Journal of Aerospace Engineering, July 1989 
Khoshnevis, B. A. Carlson, N. Leach, \& M. Thangavelu, Contour Crafting Simulation Plan for Lunar Settlement Infrastructure Buildup, ASCE Earth \& Space Conference, Pasadena, CA, April 2012, pp 14581467

Khoshnevis, B. M. P. Bodiford, K. H. Burks, E. Ethridge, D. Tucker, W. Kim, H. Toutanji, M.R. Fiske, "Lunar Contour Crafting - A novel technique for ISRU based habitat development," American Institute of Aeronautics and Astronautics Conference, Reno, January 2005.

Khoshnevis, B. D. Hwang, K. Yao and Z. Yeh, (2006) "Mega-Scale Fabrication using Contour Crafting," International Journal of Industrial \& Systems Engineering., Vol 1, No. 3, pp 301-320.

Khoshnevis, B. “Automated Construction by Contour Crafting (2004) - Related Robotics and Information Technologies," Journal of Automation in Construction - Special Issue: The best of ISARC 2002, Edited by W. C. Stone, Vol 13, Issue 1, pp 5-19.

Khoshnevis, B. and G. Bekey, (2002) "Automated Construction using Contour Crafting - Applications on Earth and Beyond," Journal of Rapid Prototyping, Vol 9, No 2, pp 1-8, 2003 (Winner of Best Paper Award at ISARC 2002).

Khoshnevis, B. M. Yoozbashizadeh, Y Chen, " Metallic Part Fabrication using Selective Inhibiton Sintering", Rapid Prototyping Journal, Vol 18, Iss 2, 2012, pp 144-153.

Khoshnevis, B, S. Bukkapatnam, H. Kwan, and J. Sato, (2001) "Experimental Investigation of Contour Crafting using Ceramic Materials," Journal of Rapid Prototyping, Vol. 7, No. 1, pp.32-41.

Kwon, H., S. Bukkapatnam, B. Khoshnevis, J. Saito, (2002) "Effect of orifice shape in Contour Crafting of Ceramic Materials", Journal of Rapid Prototyping, Vol. 8, No. 3, pp. 147-160.

Neil Leach, Xu Weiguo (eds.) Machinic Processes, 2 Vols., Beijing, China Architecture and Building Press, 2010, ISBN 978-7-112-12622-4; ISBN 978-7-112-12518-0

Neil Leach (ed.), Digital Cities, London: Wiley, 2009, ISBN 978-0470773000

Neil Leach, David Turnbull, Chris Williams (eds.), Digital Tectonics, London: Wiley, 2004, ISBN 0470857293

Neil Leach, Philip Yuan (eds.), Fabricating the Future, Shanghai: Tongji University Press, 2012.

Lumpkin F., Marichalar J., Piplica, A., (2007) Plume Impingement to the Lunar Surface: A Challenging Problem for DSMC NASA Johnson Space Center \& Jacobs Engineering - ESCG

Mason, C.C. (1970)Comparison of Actual versus Predicted Lunar Surface Erosion Caused by Apollo 11 Descent Engine, Geological Society of America Bulletin v. 81 no. 6 p. 1807-1812.

Mendell, Wendell W.,(1985) Edited by Lunar Bases and space activities of the $21^{\text {st }}$ century /. - Lunar and Planetary Institute, $1985.24 \mathrm{~cm}$. Papers from a NASA-sponsored, public symposium hosted by the National Academy of Sciences in Washington, D.C., Oct. 29- 31, 1984 ISBN 09428620233 
Mendell, Wendell.W.., Kyle Fairchild Edited by(1988). Report of the In Situ Resources Utilization Workshop : proceedings of a workshop cosponsored by National Aeronautics and Space Administration .. [et al.] ; and hosted by United Technologies Corporation, Lake Buena Vista, FLorida, January 28-30, 1987 / - NASA, 1988 (NASA CP 3017).

Metzger, P., Lane JE., (2008) Cratering and Blowing Soil by Rocket Engines During Lunar Landings

NASA's Exploration Systems Architecture Study(2005).Exploration Systems Mission

Directorate(ESMD)NASA Headquarters, Washington DC., NASA-TM-2005-214062.

NASA Office of Exploration Technical Studies Report(1988), Technical Memorandum NASA-TM-19884075, Vol1-3, NASA Hq. Washington DC.

New Frontiers in the Solar System: An Integrated Exploration Strategy(2003) - The National Academies Press, 2003.xv, 232 p.

Roberts L., (1966)The interaction of a rocket exhaust with the lunar surface. Nato-Agard Specialists' Meeting; Apr. 20-24, 1964; Marseille; France

Romine, G.L. , Reisert, T.D. , Gliozzi, J. , " Site alteration effects from rocket exhaust impingement during a simulated Viking Mars landing. Part 1: Nozzle development and physical site alternation," NASA-CR-2252, July 1973.

Schrunk, David, Sharpe Burton, Cooper Bonnie, and Thangavelu Madhu (2007). The Moon: Resources, Future Development, and Settlement, Second Edition Springer Praxis Books. 608 pages.

Sengupta et al (2012), Mars Lander Engine Plume Impingement Environment of the Mars Science Laboratory, ASCE Earth and Space Conference, Pasadena CA.

Simon, Tom and Sacksteder, Kurt.,(2007)NASA In-Situ Resource Utilization Development and Incorporation Plans, Technology Exchange Conference, Galveston Texas, NASA JSC and NASA GRC, November 2007.

Spudis P.D. (2008) Lunar Polar Exploration: Questions, Issues, and Missions. Lunar Planet. Sci. XXXIX, 1359.

Spudis P.D. (1996) The Once and Future Moon. Smithsonian Institution University Press, Washington DC, $308 \mathrm{pp}$.

Spudis P.D. (2006) Ice on the Moon. The Space Review, http://www.thespacereview.com/article/740/1

Spudis P.D. (2008) Lunar Exploration, Past and Future. Special Volume on the 50th Anniversary of the National Aeronautics and Space Administration, Washington DC, 118-127.

Thangavelu, M.(1993) MALEO: Modular Assembly in Low Earth Orbit. An Alternative Strategy for Lunar Base Establishment, Journal of the British Interplanetary Society, January 1993

Thangavelu M., et al.,(1999) The Exploration of Mars: Crew Surface Activities Space Exploration Studio Team Project, Aerospace Eng. USC.http://www.lpi.usra.edu/publications/reports/CB-979/usc.pdf 
Thangavelu, M.(2000)., Lunar Rock Structures, Return to the Moon 1l, pp106-08 Proceedings of the 2000 Lunar Development Conference, Las Vegas, NV. Edited and published by the Space Studies Institute, NJ.ISBN 0-9701278-0-4

Thangavelu M.et al., (2003), Elements of Sustainable Lunar Base in the South Polar Region, International Lunar Conference, Hawaii, http://www.spaceagepub.com/pdfs/Khaled.pdf

Thangavelu M., (2003), CONCEPT FOR A LUNAR HUMANITY CENTER AND RETIREMENT COMPLEX, AIAA 2003-6314, Space 200323 - 25 September 2003, Long Beach, California

Thangavelu M., et al., (2005) USC Hercules Program for Return to the Moon, AIAA-2005-6791 Space 2005, Long Beach, California, Aug. 30-1, 2005, University of Southern California, Los Angeles, CA $90089 \mathrm{http}: / /$ astronautics.usc.edu/hercules.htm

Thangavelu, M., et al., (2007) Return to the Moon : Jules Verne Project Fall 2006 Team Project, ASTE527 Space Exploration Architecture Concept Synthesis Studio, AIAA Space 2007 Conference, September 2007, Long Beach, CA Astronautics and Space Technology Division(ASTD), University of Southern California, CA 90089-1191

Thangavelu, M., et al (2007) Human Space Activities : The Next Fifty Years, USC School of Architecture Faculty Adviser : Madhu Thangavelu, AIAA Space 2007 Conference, September 2007, Long Beach, California Arch 599 Graduate Seminar in Human Space Exploration, Fall 2006, School of Architecture, University of Southern California. Los Angeles, CA 90089-1191

Thangavelu, M., (2008) "Critical Strategies for Return to the Moon: Altair Dust Mitigation and Real Time Teleoperations Concepts," Joint annual meeting of LEAG-ICEUM-SRR, \# 4056, Cape Canaveral, FL, Oct. 2008.

Thangavelu, M., Mekonnen, E. (2009) Preliminary Infrastructure Development for Altair Sortie Operations, AIAA Space 2009 Conference, September 2009, Pasadena, California

Thangavelu, M.et al., (2009) Return to the Moon: Looking Glass 204, AIAA Space 2009 Conference, September 2009, Pasadena, California

Thangavelu M., (2010), Living on the Moon, Encyclopedia of Aerospace Engineering, John Wiley and Sons, London, UK.

Toups, L., \& Kennedy, K. J. (2008). Constellation Architecture Team-Lunar: Lunar Habitat Concepts. AIAA SPACE 2008 Conference and Exposition, 9-11 Sep. 2008. San Diego, CA, United States : Johnson Space Center .

Toutanji, M.R. Fiske, "Lunar Contour Crafting - A novel technique for ISRU based habitat development," American Institute of Aeronautics and Astronautics Conference, Reno, January 2005. 